\title{
Natural Product Evodiamine with Borate Trigger Unit: \\ Discovery of Potent Antitumor Agents against Colon Cancer
}

Xinglin $\mathrm{Li}, \ddagger^{\mathrm{a}}$ Shanchao $\mathrm{Wu}, \ddagger^{\mathrm{b}}$ Guoqiang Dong, $\ddagger^{\mathrm{b}}$ Shuqiang Chen ${ }^{\mathrm{b}}$, Zonglin Ma, ${ }^{a}$ Dan Liu, ${ }^{* a}$ and Chunquan Sheng ${ }^{* b}$

\section{Table of contents}

1. General information.

2. General experimental procedure for synthesis of borate derivatives.

3. The synthesis of 4-(chloromethyl)phenyl acetate

4. In vitro cytotoxicity assay.

5. Apoptosis detection and cell-cycle arrest assay.

6. Top1/Top2 inhibitory activity assay.

7. The binding modes of selected compounds with Top1 and Top2.

8. Determination of in vitro metabolic stability in mice liver microsomes.

9. Tubulin polymerization inhibitory activity assay. $\quad$ S24

10. cLogP prediction. $\quad \mathrm{S} 24$

11. Relative drug release by hydrogen peroxide.

12. Relative drug release by HCT116 cells. $\quad \mathrm{S} 28$

13. In vivo antitumor activity. $\quad \mathrm{S} 32$

14. ${ }^{1} \mathrm{H}$ NMR and ${ }^{13} \mathrm{C}$ NMR spectrums.

15. HPLC purity of representative compounds.

16. Certificate of STR analysis. $\quad$ S36

17. Reference. $\quad$ S36 


\section{General Information}

All reagents and solvents are commercially available and applied without further purification. Solvent was dried using $4 \AA$ molecular sieve. ${ }^{1} \mathrm{H}$ and ${ }^{13} \mathrm{C}$ NMR raw data were collected by a Bruker AMX500 (600MHz) spectrometer and spectrums were exported through MestReNova software. Deuterated solvent included DMSO- $d_{6}$, $\mathrm{CDCl}_{3}$ and Acetone- $d_{6}$, teramethylsilane used as internal standard. The chemical shifts $(\delta)$ are reported in parts per million (ppm) and the coupling constant $(J)$ unit is $\mathrm{Hz}$. High resolution mass spectrometry (HRMS) was obtained through an Agilent 6538 UHD Accurate-Mass ultra performance liquid chromatography quadrupole time-of-flight mass (UPLC-QTOF/MS) spectrometer. HPLC analyses were performed on an Agilent 1206, using water and methanol as mobile phase. Flash chromatography carried out on silica gel 100-200 mesh with newly configured eluent.

\section{General experimental procedure for synthesis of borate derivatives}<smiles>CCOc1ccc2[nH]c3c(c2c1)CCN1C(=O)c2cc(F)ccc2N(C)C31</smiles>

3-Fluoro-14-methyl-5-oxo-5,7,8,13,13b,14-hexahydroindolo[2',3' :3,4]pyrido[2,1-b lquinazolin-10-yl trifluoromethanesulfonate (2a). Compound 1a (500.0 mg, 1.52 mmol, 1.0 equiv) was dissolved in dichloromethane (DCM) $(50 \mathrm{~mL})$ under the protection of nitrogen at $0{ }^{\circ} \mathrm{C}$. Then, pyridine $(0.5 \mathrm{~mL}, 5.93 \mathrm{mmol}, 4.0$ equiv) was added dropwise to the solution. After stirring $10 \mathrm{~min}$, trifluoromethanesulfonic anhydride $\left(\mathrm{Tf}_{2} \mathrm{O}\right)(0.3 \mathrm{~mL}, 1.83 \mathrm{mmol}, 1.2$ equiv) was added slowly and further stirred for $2 \mathrm{~h}$. After reaction, the solvent was removed under vacuum, and the residue was directly purified through flash column chromatography on silica gel (Petroleum ether/Ethyl acetate $=8: 1-4: 1, \mathrm{v} / \mathrm{v})$ to afford 2a as a white solid $(600.0 \mathrm{mg}$, yield 87\%). ${ }^{1} \mathrm{H}$ NMR (600 MHz, DMSO- $\left.d_{6}\right): \delta=11.65(\mathrm{~s}, 1 \mathrm{H}), 7.64(\mathrm{~d}, J=2.4 \mathrm{~Hz}, 1 \mathrm{H})$, $7.54(\mathrm{dd}, J=8.4,3.0 \mathrm{~Hz}, 1 \mathrm{H}), 7.49(\mathrm{~d}, J=9.0 \mathrm{~Hz}, 1 \mathrm{H}), 7.39(\mathrm{td}, J=8.4,3.0 \mathrm{~Hz}, 1 \mathrm{H})$, $7.20(\mathrm{dd}, J=9.0,4.8 \mathrm{~Hz}, 1 \mathrm{H}), 7.17(\mathrm{dd}, J=9.0,2.4 \mathrm{~Hz}, 1 \mathrm{H}), 6.14(\mathrm{~s}, 1 \mathrm{H}), 4.65-4.58$ 
(m, 1H), $3.22(\mathrm{ddd}, J=12.6,10.2,6.0 \mathrm{~Hz}, 1 \mathrm{H}), 2.88$ (q, $J=10.2 \mathrm{~Hz}, 2 \mathrm{H}), 2.69$ (s, $3 \mathrm{H})$. HRMS (ESI) calcd for $\mathrm{C}_{20} \mathrm{H}_{16} \mathrm{~F}_{4} \mathrm{~N}_{3} \mathrm{O}_{4} \mathrm{~S}[\mathrm{M}+\mathrm{H}]^{+}=470.0792$, found 470.0800. The preparation of compound $\mathbf{2} \mathbf{b}$ was similar to this procedure.<smiles>CCOc1ccc2[nH]c3c(c2c1)CCN1C(=O)c2ccccc2N(C)C31</smiles>

14-Methyl-5-oxo-5,7,8,13,13b,14-hexahydroindolo[2',3' :3,4]pyrido[2,1-b]quinazolin-10-yl trifluoromethanesulfonate (2b). Pale yellow solid, yield 86\%. ${ }^{1} \mathrm{H}$ NMR $\left(600 \mathrm{MHz}, \mathrm{DMSO}-d_{6}\right): \delta=11.52(\mathrm{~s}, 1 \mathrm{H}), 7.79(\mathrm{dd}, J=7.8,1.2 \mathrm{~Hz}, 1 \mathrm{H}), 7.61(\mathrm{~d}, J=$ $2.4 \mathrm{~Hz}, 1 \mathrm{H}), 7.52-7.45(\mathrm{~m}, 2 \mathrm{H}), 7.15(\mathrm{dd}, J=9.0,2.4 \mathrm{~Hz}, 1 \mathrm{H}), 7.06$ (d, $J=8.4 \mathrm{~Hz}$, 1H), $7.00-6.89(\mathrm{~m}, 1 \mathrm{H}), 6.18(\mathrm{~s}, 1 \mathrm{H}), 4.63(\mathrm{dd}, J=13.2,4.8 \mathrm{~Hz}, 1 \mathrm{H}), 3.22(\mathrm{td}, J=$ 12.6, $4.8 \mathrm{~Hz}, 1 \mathrm{H}), 2.96-2.87(\mathrm{~m}, 4 \mathrm{H}), 2.82(\mathrm{dd}, J=15.6,4.8 \mathrm{~Hz}, 1 \mathrm{H})$.<smiles>CN1c2ccc(F)cc2C(=O)N2CCc3c([nH]c4ccc(B5OC(C)(C)C(C)(C)O5)cc34)C21</smiles>

3-Fluoro-14-methyl-10-(4,4,5,5-tetramethyl-1,3,2-dioxaborolan-2-yl)-8,13,13b,14tetrahydroindolo $\left[2^{\prime}, 3^{\prime}: 3,4\right]$ pyrido $[2,1-b]$ quinazolin-5(7H)-one (3a). Compound 2 (470.0 mg, $1.0 \mathrm{mmol}, 1.0$ equiv), bis(pinacolato)diboron (356.0 mg, $1.4 \mathrm{mmol}, 1.2$ equiv), $\mathrm{Pd}(\mathrm{dppf}) \mathrm{Cl}_{2}$ (41.0 mg, $0.1 \mathrm{mmol}, 0.1$ equiv), KOAc (294.0 mg, $3.0 \mathrm{mmol}, 3.0$ equiv) were added in dry dioxane $(30 \mathrm{~mL})$. The resulting mixture was refluxed under nitrogen atmosphere for $8 \mathrm{~h}$. After reaction, the solvent was removed under vacuum and the residue was directly purified by flash column chromatography on silica gel (Petroleum ether/Ethyl acetate $=8: 1-4: 1, \mathrm{v} / \mathrm{v}$ ) to afford 3a as a pale yellow solid (400.0 mg, yield 85\%). ${ }^{1} \mathrm{H}$ NMR (600 MHz, DMSO- $\left.d_{6}\right): \delta=11.34$ (s, 1H), 7.89 (s, 1H), $7.54(\mathrm{dd}, J=9.0,3.0 \mathrm{~Hz}, 1 \mathrm{H}), 7.45(\mathrm{~d}, J=7.8 \mathrm{~Hz}, 1 \mathrm{H}), 7.39(\mathrm{td}, J=8.4,3.0 \mathrm{~Hz}$, 1H), 7.36 (d, $J=8.4 \mathrm{~Hz}, 1 \mathrm{H}), 7.20$ (dd, $J=9.0,4.8 \mathrm{~Hz}, 1 \mathrm{H}), 6.10$ (s, 1H), 4.63 (dd, $J$ $=13.2,4.2 \mathrm{~Hz}, 1 \mathrm{H}), 3.21(\mathrm{td}, J=12.6,4.8 \mathrm{~Hz}, 1 \mathrm{H}), 2.97-2.81(\mathrm{~m}, 2 \mathrm{H}), 2.65(\mathrm{~s}, 3 \mathrm{H})$, $1.30(\mathrm{~s}, 12 \mathrm{H}) \cdot{ }^{13} \mathrm{C}$ NMR (150 MHz, DMSO-d $)_{6} \delta=163.44,157.71\left(\mathrm{~d}, \mathrm{~J}_{c-f}=237.3\right.$ 
$\mathrm{Hz}), 146.53,139.20,134.85,130.36,128.39,126.38,126.02,122.73\left(\mathrm{~d}, \mathrm{~J}_{c-f}=7.05\right.$ $\mathrm{Hz}), 122.45\left(\mathrm{~d}, \mathrm{~J}_{c-f}=7.5 \mathrm{~Hz}\right), 121.03\left(\mathrm{~d}, \mathrm{~J}_{c-f}=22.8 \mathrm{~Hz}\right), 113.86\left(\mathrm{~d}, \mathrm{~J}_{c-f}=23.25 \mathrm{~Hz}\right)$. 112.72, 111.62, 83.63, 69.60, 40.69, 37.15, 25.15, 19.88. HRMS (ESI) calcd for $\mathrm{C}_{25} \mathrm{H}_{28} \mathrm{BFN}_{3} \mathrm{O}_{3}[\mathrm{M}+\mathrm{H}]^{+}=448.2202$, found 448.2210 . The preparation of compound 3b was similar to this procedure.

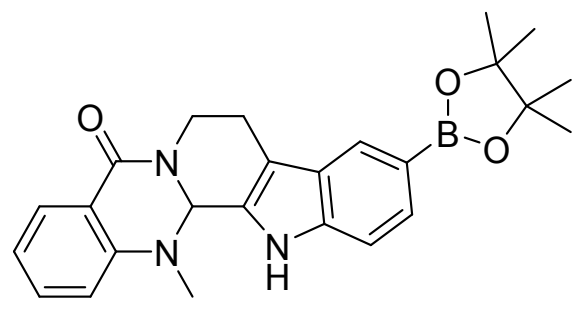

14-Methyl-10-(4,4,5,5-tetramethyl-1,3,2-dioxaborolan-2-yl)-8,13,13b,14 tetrahydroindolo[2',3':3,4]pyrido[2,1-b]quinazolin-5(7H)-one (3b). White solid, yield 93\%. ${ }^{1} \mathrm{H}$ NMR (600 MHz, DMSO- $\left.d_{6}\right): \delta=11.25(\mathrm{~s}, 1 \mathrm{H}), 7.88(\mathrm{~s}, 1 \mathrm{H}), 7.82$ (d, $J=7.8$ $\mathrm{Hz}, 1 \mathrm{H}), 7.50$ (t, $J=7.8 \mathrm{~Hz}, 1 \mathrm{H}), 7.46$ (d, $J=8.4 \mathrm{~Hz}, 1 \mathrm{H}), 7.38(\mathrm{~d}, J=8.4 \mathrm{~Hz}, 1 \mathrm{H})$, $7.08(\mathrm{~d}, J=7.8 \mathrm{~Hz}, 1 \mathrm{H}), 6.99(\mathrm{t}, J=7.8 \mathrm{~Hz}, 1 \mathrm{H}), 6.16(\mathrm{~s}, 1 \mathrm{H}), 4.66(\mathrm{dd}, J=12.6,4.8$ $\mathrm{Hz}, 1 \mathrm{H}), 3.23(\mathrm{td}, J=12.6,4.8 \mathrm{~Hz}, 1 \mathrm{H}), 2.97-2.82(\mathrm{~m}, 5 \mathrm{H}), 1.32(\mathrm{~s}, 12 \mathrm{H}) .{ }^{13} \mathrm{C} \mathrm{NMR}$ (150 MHz, DMSO- $\left.d_{6}\right): \delta=164.62,149.27,139.04,133.90,131.39,128.46,128.31$, 126.26, 126.17, 120.89, 119.87, 118.14, 112.58, 111.62, 83.61, 70.13, 41.24, 40.55, 36.98, 25.22, 19.81. HRMS (ESI) calcd for $\mathrm{C}_{25} \mathrm{H}_{29} \mathrm{BN}_{3} \mathrm{O}_{3}[\mathrm{M}+\mathrm{H}]^{-}=430.2296$, found 430.2316 .<smiles>CN1c2ccc(F)cc2C(=O)N2CCc3c([nH]c4ccc(Br)cc34)C21</smiles>

\section{3-Fluoro-14-methyl-10-(trifluoro-l4-boranyl)-8,13,13b,14-tetrahy-droindolo[ $2^{\prime}, 3^{\prime}$} :3,4]pyrido[2,1-b]quinazolin-5(7H)-one, potassium salt $(4 a)$. To a solution of aqueous potassium hydrogen fluoride $\left(\mathrm{KHF}_{2}\right)(0.2 \mathrm{~mL}, 4.5 \mathrm{M}, 1.0 \mathrm{mmol}, 5.7$ equiv) in methanol (2 mL), compound 3 (100.0 mg, $0.2 \mathrm{mmol}, 1.0$ equiv) was added. The resulting mixture was stirred at room temperature for $0.5 \mathrm{~h}$ and concentrated in vacuo, then acetone $(10 \mathrm{~mL})$ was added and further heated to $57^{\circ} \mathrm{C}$ for $0.5 \mathrm{~h}$. After that, the 
hot suspension was filtered immediately and the filtrate was concentrated in vacuum. The residue was recrystallized with DCM $(10 \mathrm{~mL})$ to afford the compound $4 \mathbf{a}$ as a yellow solid (95.0 mg, yield 68\%). which was used directly for the next step without further purification. The preparation of compound $\mathbf{4 b}$ was similar to this procedure. ${ }^{1} \mathrm{H}$ NMR (600 MHz, Acetone- $\left.d 6\right): \delta=9.05$ (s, 1H), 6.93 (s, 1H), 6.87 (dd, $J=9.0$, $3.0 \mathrm{~Hz}, 1 \mathrm{H}), 6.64(\mathrm{~d}, J=7.8 \mathrm{~Hz}, 1 \mathrm{H}), 6.52(\mathrm{td}, J=8.4,3.0 \mathrm{~Hz}, 1 \mathrm{H}), 6.44(\mathrm{dd}, J=8.4$, $4.8 \mathrm{~Hz}, 2 \mathrm{H}), 5.21(\mathrm{~s}, 1 \mathrm{H}), 3.98(\mathrm{ddd}, J=12.6,4.2,2.4 \mathrm{~Hz}, 1 \mathrm{H}), 2.45(\mathrm{ddd}, J=15.6$, $10.2,6.0 \mathrm{~Hz}, 1 \mathrm{H}), 2.15$ (dd, $J=4.8,1.2 \mathrm{~Hz}, 1 \mathrm{H}), 2.06(\mathrm{~s}, 4 \mathrm{H})$.<smiles>CN1c2ccccc2C(=O)N2CCc3c([nH]c4ccc(Br)cc34)C21</smiles>

\section{4-Methyl-10-(trifluoro-l4-boranyl)-8,13,13b,14-tetrahy-droindolo[2',3' :3,4]pyri} do[2,1-b]quinazolin-5(7H)-one, potassium salt (4b). Yellow solid, yield $68 \% .{ }^{1} \mathrm{H}$ NMR (600 MHz, Acetone- $\left.d_{6}\right): \delta=9.78(\mathrm{~s}, 1 \mathrm{H}), 7.94(\mathrm{dd}, J=7.8,1.2 \mathrm{~Hz}, 1 \mathrm{H}), 7.67$ (s, 1H), 7.46 (ddd, $J=8.4,7.8,1.8 \mathrm{~Hz}, 1 \mathrm{H}), 7.37$ (d, $J=7.8 \mathrm{~Hz}, 1 \mathrm{H}), 7.17(\mathrm{~d}, J=7.8$ Hz, 1H), 7.08 (d, $J=7.8 \mathrm{~Hz}, 1 \mathrm{H}), 7.05-7.00$ (m, 1H), 5.98 (d, $J=1.4 \mathrm{~Hz}, 1 \mathrm{H}), 4.75$ (ddd, $J=12.6,5.4,1.8 \mathrm{~Hz}, 1 \mathrm{H}), 3.18(\mathrm{ddd}, J=12.6,11.4,4.8 \mathrm{~Hz}, 1 \mathrm{H}), 2.94-2.90$ (m, $1 \mathrm{H}), 2.83(\mathrm{~s}, 4 \mathrm{H})$.<smiles>CN1c2ccc(F)cc2C(=O)N2CCc3c([nH]c4ccc(B(O)O)cc34)C21</smiles>

(3-Fluoro-14-methyl-5-oxo-5,7,8,13,13b,14-hexahydroindolo[2',3' :3,4]pyrido[2,1b]quinazolin-10-yl)boronic acid (5a). Trimethylsilyl chloride (TMS-Cl) (60 $\mu \mathrm{L}, 0.44$ mmol, 3.1 equiv) was slowly added to a suspension of compound $4 \mathbf{a}(118.0 \mathrm{mg}, 0.28$ mmol, 1.0 equiv) in the mixture solvent of water ( $15 \mu \mathrm{L}, 0.83 \mathrm{mmol}, 3.1$ equiv) and acetonitrile $(3 \mathrm{~mL})$. The resulting mixture was stirred for $1 \mathrm{~h}$ at room temperature and diluted with ethyl acetate $(10 \mathrm{~mL})$. Then it was quenched with saturated sodium bicarbonate solution $(0.3 \mathrm{~mL})$, dried over sodium sulfate and concentrated under reduced pressure. The crude product was recrystallized with DCM $(10 \mathrm{~mL})$ to afford 
the compound 5a as a pale yellow solid (98.0 mg, yield 98\%). ${ }^{1} \mathrm{H}$ NMR (600 MHz, DMSO- $\left.d_{6}\right): \delta=11.19(\mathrm{~s}, 1 \mathrm{H}), 8.03(\mathrm{~s}, 1 \mathrm{H}), 7.76(\mathrm{~s}, 2 \mathrm{H}), 7.61-7.57(\mathrm{~m}, 1 \mathrm{H}), 7.55$ (dd, $J=8.4,3.0 \mathrm{~Hz}, 1 \mathrm{H}), 7.39$ (td, $J=9.0,3.0 \mathrm{~Hz}, 1 \mathrm{H}), 7.32(\mathrm{~d}, J=8.4 \mathrm{~Hz}, 1 \mathrm{H}), 7.20$ (dd, $J=9.0,4.8 \mathrm{~Hz}, 1 \mathrm{H}), 6.09$ (s, 1H), $4.71-4.59$ (m, 1H), 3.22 (ddd, $J=12.6,10.2$, $6.0 \mathrm{~Hz}, 1 \mathrm{H}), 2.91-2.86(\mathrm{~m}, 2 \mathrm{H}), 2.67(\mathrm{~s}, 3 \mathrm{H})$. HRMS (ESI) calcd for $\mathrm{C}_{19} \mathrm{H}_{18} \mathrm{BFN}_{3} \mathrm{O}_{3}$ $[\mathrm{M}+\mathrm{H}]^{+}=366.1420$, found 366.1430 . The preparation of compound $\mathbf{5 b}$ was similar to this procedure.<smiles>CN1c2ccccc2C(=O)N2CCc3c([nH]c4ccc(B(O)O)cc34)C21</smiles>

(14-Methyl-5-oxo-5,7,8,13,13b,14-hexahydroindolo[2',3':3,4]pyrido[2,1-b]quinaz olin-10-yl)boronic acid (5b). Pale yellow solid, yield 60\%. ${ }^{1} \mathrm{H}$ NMR (600 MHz, DMSO- $\left.d_{6}\right): \delta=11.06(\mathrm{~s}, 1 \mathrm{H}), 7.99(\mathrm{~s}, 1 \mathrm{H}), 7.79(\mathrm{dd}, J=7.8,1.2 \mathrm{~Hz}, 1 \mathrm{H}), 7.76(\mathrm{~s}$, 2H), 7.56 (d, $J=7.8 \mathrm{~Hz}, 1 \mathrm{H}), 7.49-7.42(\mathrm{~m}, 1 \mathrm{H}), 7.29$ (d, $J=8.4 \mathrm{~Hz}, 1 \mathrm{H}), 7.04$ (d, $J$ $=7.8 \mathrm{~Hz}, 1 \mathrm{H}), 6.96(\mathrm{t}, J=7.2 \mathrm{~Hz}, 1 \mathrm{H}), 6.10(\mathrm{~s}, 1 \mathrm{H}), 4.63(\mathrm{dd}, J=12.04 .8 \mathrm{~Hz}, 1 \mathrm{H})$, $3.20(\mathrm{td}, J=12.6,4.2 \mathrm{~Hz}, 1 \mathrm{H}), 2.96-2.83(\mathrm{~m}, 4 \mathrm{H}), 2.79$ (dd, $J=15.6,4.8 \mathrm{~Hz}, 1 \mathrm{H})$. ${ }^{13} \mathrm{C}$ NMR $\left(150 \mathrm{MHz}, \mathrm{DMSO}-d_{6}\right) \delta=164.69,149.30,138.45,133.89,130.78,128.46$, $128.43,126.10,125.68,120.79,119.82,118.02$, 112.38, 111.02, 70.18, 41.30, 36.88, 19.99. HRMS (ESI) calcd for $\mathrm{C}_{19} \mathrm{H}_{19} \mathrm{BN}_{3} \mathrm{O}_{3}[\mathrm{M}+\mathrm{H}]^{-}=348.1514$, found 348.1529 .<smiles>CN1c2ccc(F)cc2C(=O)N2CCc3c(n(C(=O)OCc4ccccc4)c4ccc(O)cc34)C21</smiles>

tert-Butyl 3-fluoro-10-hydroxy-14-methyl-5-oxo-7,8,13b,14- tetrahydroindolo $\left[2^{\prime}, 3^{\prime}: 3,4\right]$ pyrido[2,1-b]quinazoline-13(5H)-carboxylate (6a). Compound 1a (500.0 $\mathrm{mg}, 1.48 \mathrm{mmol}, 1.0$ equiv), $\mathrm{Boc}_{2} \mathrm{O}$ (970.0 mg, $4.45 \mathrm{mmol}, 3.0$ equiv) and dimethylaminopyridine (DMAP) (18.0 mg, $0.15 \mathrm{mmol}, 0.1$ equiv) were dissolved in tetrahydrofuran (THF) $(20 \mathrm{~mL})$. The reaction solution was stirred for $4 \mathrm{~h}$ at room temperature, half volume of the solvent was removed under vacuum, then $\mathrm{K}_{2} \mathrm{CO}_{3}(1.1$ 
g, $7.41 \mathrm{mmol}, 5.0$ equiv) and methanol $(10 \mathrm{~mL})$ were added. The resulting mixture was further stirred for $4 \mathrm{~h}$ at room temperature. Subsequently, acetic acid (1 mL) was added to quench the reaction and directly purified through flash column chromatography on silica gel (Petroleum ether/Ethyl acetate $=8: 1-4: 1, \mathrm{v} / \mathrm{v}$ ) to afford 6a as white solid (400.0 mg, yield 62\%). ${ }^{1} \mathrm{H}$ NMR (600 MHz, DMSO- $\left.d_{6}\right): \delta=9.35$ (s, $1 \mathrm{H}), 7.98(\mathrm{~d}, J=9.0 \mathrm{~Hz}, 1 \mathrm{H}), 7.59(\mathrm{dd}, J=9.0,3.0 \mathrm{~Hz}, 1 \mathrm{H}), 7.41(\mathrm{td}, J=8.6,3.1 \mathrm{~Hz}$, $1 \mathrm{H}), 7.26(\mathrm{dd}, J=9.0,4.6 \mathrm{~Hz}, 1 \mathrm{H}), 6.94(\mathrm{~d}, J=2.4 \mathrm{~Hz}, 1 \mathrm{H}), 6.87$ (dd, $J=9.0,2.4 \mathrm{~Hz}$, 1H), $6.15(\mathrm{~s}, 1 \mathrm{H}), 4.61$ (dd, $J=12.6,4.2 \mathrm{~Hz}, 1 \mathrm{H}), 3.13$ (td, $J=12.6,3.6 \mathrm{~Hz}, 1 \mathrm{H}), 2.91$ $(\mathrm{m}, J=13.2 \mathrm{~Hz}, 1 \mathrm{H}), 2.80-2.63(\mathrm{~m}, 1 \mathrm{H}), 2.36(\mathrm{~s}, 3 \mathrm{H}), 1.45(\mathrm{~s}, 9 \mathrm{H})$. The preparation of compound $\mathbf{6 b}$ was similar to this procedure.<smiles>CN1c2ccccc2C(=O)N2CCc3c(n(C(=O)OC(C)(C)C)c4ccc(O)cc34)C21</smiles>

tert-Butyl 10-hydroxy-14-methyl-5-oxo-7,8,13b,14-tetrahydroindolo $\quad\left[2^{\prime}, 3^{\prime}: 3,4\right]$ pyrido[2,1-b]quinazoline-13(5H)-carboxylate (6b). White solid, yield $58 \%$. ${ }^{1} \mathrm{H}$ NMR (600 MHz, DMSO- $\left.d_{6}\right): \delta=9.37(\mathrm{~s}, 1 \mathrm{H}), 7.99$ (d, $\left.J=9.0 \mathrm{~Hz}, 1 \mathrm{H}\right), 7.89$ (dd, $J=$ 7.2, $1.2 \mathrm{~Hz}, 1 \mathrm{H}), 7.51(\mathrm{dd}, J=13.2,4.8 \mathrm{~Hz}, 1 \mathrm{H}), 7.15(\mathrm{~d}, J=8.4 \mathrm{~Hz}, 1 \mathrm{H}), 7.09$ (t, $J=$ $7.8 \mathrm{~Hz}, 1 \mathrm{H}), 6.95(\mathrm{~d}, J=2.4 \mathrm{~Hz}, 1 \mathrm{H}), 6.87(\mathrm{dd}, J=9.0,2.4 \mathrm{~Hz}, 1 \mathrm{H}), 6.14(\mathrm{~s}, 1 \mathrm{H})$, $4.60(\mathrm{dd}, J=12.6,4.8 \mathrm{~Hz}, 1 \mathrm{H}), 3.10(\mathrm{td}, J=12.0,3.6 \mathrm{~Hz}, 1 \mathrm{H}), 2.91(\mathrm{~d}, J=14.4 \mathrm{~Hz}$, 1H), $2.79-2.65(\mathrm{~m}, 1 \mathrm{H}), 2.44(\mathrm{~s}, 3 \mathrm{H}), 1.44(\mathrm{~s}, 9 \mathrm{H}) .{ }^{13} \mathrm{C}$ NMR (150 MHz, DMSO- $\left.d_{6}\right)$ : $\delta=163.94,154.17,150.46,149.46,133.43,130.50,128.80,128.66,128.40,121.89$, $121.79,121.63,119.85,116.40,115.10,104.21,84.26,68.28,38.37,35.10,27.86$, 20.59 .<smiles>CN1c2ccc(F)cc2C(=O)N2CCc3c(n(C(=O)OC(C)(C)C)c4ccc(OCc5ccc(B(O)O)cc5)cc34)C21</smiles>

(4-(((13-(tert-Butoxycarbonyl)-3-fluoro-14-methyl-5-oxo-5,7,8,13,13b,14-hexahyd 


\section{roindolo[2',3':3,4]pyrido[2,1-b]quinazolin-10-yl)oxy)methyl)phenyl)boronic acid}

(7a). Compound 6a (500.0 mg, $1.48 \mathrm{mmol}, 1.0$ equiv) was dissolved in dry dimethyformamide (DMF) (15 mL) and $\mathrm{NaH}(65.0 \mathrm{mg}, 1.63 \mathrm{mmol}, 1.1$ equiv) was slowly added, then the mixture was stirred in an ice bath for $0.5 \mathrm{~h}$. The solution of 4-bromomethylphenylboronic acid in dry DMF $(3 \mathrm{~mL})$ was added dropwise into the reaction and stirred at room temperature for $8 \mathrm{~h}$. After the reaction, the $\mathrm{pH}$ was adjusted to 2 with $1 \mathrm{~N} \mathrm{HCl}$ and then poured into ice-water $(300 \mathrm{~mL})$. The crude product was obtained after filtration and lyophilization, followed by the purification through flash column chromatography on silica gel (Petroleum ether/Ethyl acetate $=5$ : $1-1: 1, \mathrm{v} / \mathrm{v})$ to afford $7 \mathbf{a}$ as a white solid $\left(170.0 \mathrm{mg}\right.$, yield 79\%). ${ }^{1} \mathrm{H}$ NMR (600 MHz, DMSO- $\left.d_{6}\right): \delta=8.06(\mathrm{~d}, J=9.0 \mathrm{~Hz}, 1 \mathrm{H}), 8.03(\mathrm{~s}, 2 \mathrm{H}), 7.80(\mathrm{~d}, J=7.8 \mathrm{~Hz}, 2 \mathrm{H}), 7.58$ (dd, $J=9.0,3.0 \mathrm{~Hz}, 1 \mathrm{H}), 7.43$ (d, $J=7.8 \mathrm{~Hz}, 2 \mathrm{H}), 7.40$ (dd, $J=8.4,3.0 \mathrm{~Hz}, 1 \mathrm{H}), 7.30$ $(\mathrm{d}, J=2.4 \mathrm{~Hz}, 1 \mathrm{H}), 7.26(\mathrm{dd}, J=9.0,4.8 \mathrm{~Hz}, 1 \mathrm{H}), 7.09(\mathrm{dd}, J=9.0,2.4 \mathrm{~Hz}, 1 \mathrm{H}), 6.16$ (s, 1H), $5.17(\mathrm{~s}, 2 \mathrm{H}), 4.62(\mathrm{dd}, J=12.0,4.8 \mathrm{~Hz}, 1 \mathrm{H}), 3.17-3.09(\mathrm{~m}, 1 \mathrm{H}), 2.99(\mathrm{~d}, J=$ $13.8 \mathrm{~Hz}, 1 \mathrm{H}), 2.75-2.68(\mathrm{~m}, 1 \mathrm{H}), 2.34$ (s, 3H), 1.44 (s, 9H). ${ }^{13} \mathrm{C}$ NMR (150 MHz, DMSO- $\left.d_{6}\right): \delta=162.82,157.90\left(\mathrm{~d}, J_{c-f}=238.05 \mathrm{~Hz}\right), 155.37,149.39,147.19,139.44$, $134.69,131.53,128.62,128.35,127.00,123.76\left(\mathrm{~d}, J_{c-f}=7.2 \mathrm{~Hz}\right), 123.49\left(\mathrm{~d}, J_{c-f}=7.5\right.$ $\mathrm{Hz}), 120.92\left(\mathrm{~d}, J_{\mathrm{c}-\mathrm{f}}=23.25 \mathrm{~Hz}\right), 120.84,116.42,115.48,113.99\left(\mathrm{~d}, J_{c-f}=23.1 \mathrm{~Hz}\right)$, 103.69, 84.50, 70.17, 68.49, 40.55, 38.45, 35.68, 27.85, 20.56. HRMS (ESI) calcd for $\mathrm{C}_{31} \mathrm{H}_{32} \mathrm{BFN}_{3} \mathrm{O}_{6}[\mathrm{M}+\mathrm{H}]^{+}=572.2363$, found 572.2371 . The preparation of compound $7 \mathbf{b}$ was similar to this procedure.<smiles>CN1c2ccccc2C(=O)N2CCc3c(n(C(=O)OC(C)(C)C)c4ccc(OCc5ccc(B(O)O)cc5)cc34)C21</smiles>

(4-(((13-(tert-Butoxycarbonyl)-14-methyl-5-oxo-5,7,8,13,13b,14-hexahydroindol o[2',3':3,4]pyrido[2,1-b]quinazolin-10-yl)oxy)methyl)phenyl)boronic acid (7b). White solid, yield 80\%. ${ }^{1} \mathrm{H}$ NMR (600 MHz, DMSO- $\left.d_{6}\right): \delta=8.09(\mathrm{~d}, J=9.0 \mathrm{~Hz}, 1 \mathrm{H})$, $8.04(\mathrm{~s}, 2 \mathrm{H}), 7.90(\mathrm{dd}, J=7.8,1.3 \mathrm{~Hz}, 1 \mathrm{H}), 7.81(\mathrm{~d}, J=8.4 \mathrm{~Hz}, 2 \mathrm{H}), 7.56-7.48(\mathrm{~m}$, 
1H), $7.44(\mathrm{~d}, J=7.8 \mathrm{~Hz}, 2 \mathrm{H}), 7.32(\mathrm{~d}, J=3.0 \mathrm{~Hz}, 1 \mathrm{H}), 7.16$ (d, $J=7.8 \mathrm{~Hz}, 1 \mathrm{H}), 7.13$ $7.06(\mathrm{~m}, 2 \mathrm{H}), 6.17(\mathrm{~s}, 1 \mathrm{H}), 5.19(\mathrm{~s}, 2 \mathrm{H}), 4.63(\mathrm{dd}, J=11.4,4.8 \mathrm{~Hz}, 1 \mathrm{H}), 3.12(\mathrm{td}, J=$ 12.6, 3.6 Hz, 1H), $3.00(\mathrm{~d}, J=13.8 \mathrm{~Hz}, 1 \mathrm{H}), 2.78-2.68(\mathrm{~m}, 1 \mathrm{H}), 2.44(\mathrm{~s}, 3 \mathrm{H}), 1.45$ (s, 9H). ${ }^{13} \mathrm{C}$ NMR $\left(150 \mathrm{MHz}, \mathrm{DMSO}-d_{6}\right) \delta=165.30,156.75,151.83,150.78,140.82$, $136.07,134.82,132.83,130.19,130.14,129.82,128.38,123.37,123.24,121.36$, 117.88, 116.83, 105.06, 85.93, 71.53, 69.65, 56.74, 41.92, 39.77, 36.56, 29.22, 22.04. HRMS (ESI) calcd for $\mathrm{C}_{31} \mathrm{H}_{33} \mathrm{BN}_{3} \mathrm{O}_{6}[\mathrm{M}+\mathrm{H}]^{-}=554.2457$, found 554.2469.<smiles>CN1c2ccc(F)cc2C(=O)N2CCc3c([nH]c4ccc(OCc5ccc(B(O)O)cc5)cc34)C21</smiles>

\section{(4-(((3-Fluoro-14-methyl-5-oxo-5,7,8,13,13b,14-hexahydroindolo[2',3':3,4]pyrido[} 2,1-b]quinazolin-10-yl)oxy)methyl)phenyl)boronic acid (8a). Compound 7a (500.0 $\mathrm{mg}, 1.48 \mathrm{mmol}, 1.0$ equiv) was dissolved in DCM (16 mL), followed by the addition of trifluoroacetic acid (TFA) (4 mL). The mixture was stirred at room temperature for $2 \mathrm{~h}$, then purified directly through flash column chromatograph on silica gel (Petroleum ether/Ethyl acetate $=5: 1-1: 1, \mathrm{v} / \mathrm{v})$ to afford 8a as a pale yellow solid (77.0 mg, yield 63\%). ${ }^{1} \mathrm{H}$ NMR (600 MHz, DMSO- $\left.d_{6}\right): \delta=10.99$ (s, 1H), 7.99 (s, 2H), $7.77(\mathrm{~d}, J=7.8 \mathrm{~Hz}, 2 \mathrm{H}), 7.51(\mathrm{dd}, J=9.0,3.0 \mathrm{~Hz}, 1 \mathrm{H}), 7.40(\mathrm{~d}, J=8.4 \mathrm{~Hz}, 2 \mathrm{H})$, $7.35(\mathrm{td}, J=8.4,3.1 \mathrm{~Hz}, 1 \mathrm{H}), 7.24(\mathrm{~d}, J=9.0 \mathrm{~Hz}, 1 \mathrm{H}), 7.15(\mathrm{dd}, J=9.0,4.2 \mathrm{~Hz}, 1 \mathrm{H})$, $7.07(\mathrm{~d}, J=2.4 \mathrm{~Hz}, 1 \mathrm{H}), 6.83(\mathrm{dd}, J=8.4,2.4 \mathrm{~Hz}, 1 \mathrm{H}), 6.03(\mathrm{~s}, 1 \mathrm{H}), 5.08(\mathrm{~s}, 2 \mathrm{H})$, $4.63-4.54(\mathrm{~m}, 1 \mathrm{H}), 3.17$ (ddd, $J=12.6,10.8,5.4 \mathrm{~Hz}, 1 \mathrm{H}), 2.85-2.74(\mathrm{~m}, 2 \mathrm{H}), 2.65$ $(\mathrm{s}, 3 \mathrm{H}) .{ }^{13} \mathrm{C} \mathrm{NMR}\left(150 \mathrm{MHz}, \mathrm{DMSO}-d_{6}\right): \delta=163.50,157.57\left(\mathrm{~d}, J_{c-f}=237.3 \mathrm{~Hz}\right)$, $152.87,146.47,140.01,134.63,132.34,130.77,126.90,126.58,122.48\left(\mathrm{~d}, J_{c-f}=7.35\right.$ $\mathrm{Hz}), 122.08\left(\mathrm{~d}, J_{c-f}=7.35 \mathrm{~Hz}\right), 121.01\left(\mathrm{~d}, J_{c-f}=23.1 \mathrm{~Hz}\right), 113.86\left(\mathrm{~d}, J_{c-f}=23.25\right.$ Hz), 113.15, 112.80, 111.88, 102.29, 70.28, 69.75, 40.84, 40.54, 37.06, 20.10. HRMS (ESI) calcd fo $\mathrm{C}_{26} \mathrm{H}_{22} \mathrm{BFN}_{3} \mathrm{O}_{4}[\mathrm{M}-\mathrm{H}]^{-}=470.1693$, found 470.1694. The preparation of compound $\mathbf{8 b}$ was similar to this procedure. 
<smiles>CN1c2ccccc2C(=O)N2CCc3c([nH]c4ccc(OCc5ccc(B(O)O)cc5)cc34)C21</smiles>

(4-(((14-Methyl-5-oxo-5,7,8,13,13b,14-hexahydroindolo[2',3':3,4]pyrido[2,1-b]qui nazolin-10-yl)oxy)methyl)phenyl)boronic acid (8b). Pale yellow solid, yield 65\%. ${ }^{1} \mathrm{H}$ NMR (600 MHz, DMSO-d 6 ): $\delta=10.90(\mathrm{~s}, 1 \mathrm{H}), 8.03$ (s, 2H), 7.79 (d, $J=7.8 \mathrm{~Hz}$, 2H), $7.79(\mathrm{~s}, 1 \mathrm{H}), 7.49-7.45(\mathrm{~m}, 1 \mathrm{H}), 7.42$ (d, $J=7.8 \mathrm{~Hz}, 2 \mathrm{H}), 7.25(\mathrm{~d}, J=9.0 \mathrm{~Hz}$, 1H), 7.07 (d, $J=2.4 \mathrm{~Hz}, 1 \mathrm{H}), 7.04$ (d, $J=7.8 \mathrm{~Hz}, 1 \mathrm{H}), 6.95$ (t, $J=7.2 \mathrm{~Hz}, 1 \mathrm{H}), 6.83$ (dd, $J=9.0,2.4 \mathrm{~Hz}, 1 \mathrm{H}), 6.10(\mathrm{~s}, 1 \mathrm{H}), 5.10$ (s, 2H), 4.62 (dd, $J=12.6,4.8 \mathrm{~Hz}, 1 \mathrm{H})$, $3.23-3.11(\mathrm{~m}, 1 \mathrm{H}), 2.93-2.83(\mathrm{~m}, 4 \mathrm{H}), 2.74(\mathrm{dd}, J=15.0,4.2 \mathrm{~Hz}, 1 \mathrm{H}) .{ }^{13} \mathrm{C} \mathrm{NMR}$ $\left(150 \mathrm{MHz}, \mathrm{DMSO}-d_{6}\right): \delta=166.05,154.24,150.57,141.38,136.00,135.27,133.54$, $133.21,129.83,128.27,128.12,122.02,121.02,119.17,114.39,114.17,113.13$, 103.57, 71.65, 42.75, 38.25, 21.40. HRMS (ESI) calcd for $\mathrm{C}_{26} \mathrm{H}_{25} \mathrm{BN}_{3} \mathrm{O}_{4}[\mathrm{M}+\mathrm{H}]^{-}=$ 454.1933, found 454.1940.<smiles>CC(C)(C)OC(=O)n1c2c(c3cc(OCc4ccc(B5OC(C)(C)C(C)(C)O5)cc4)ccc31)CCN1C(=O)c3cc(F)ccc3N(C(C)(C)C)C21</smiles>

tert-Butyl 3-fluoro-14-methyl-5-oxo-10-((4-(4,4,5,5-tetramethyl-1,3,2-dioxaborolan-2-yl)benzyl)oxy)-7,8,13b,14-tetrahydroindolo[2',3':3,4]pyrido[2,1-b]quinazoli ne-13(5H)-carboxylate (9a). Compound $6 \mathbf{6 a}(100.0 \mathrm{mg}, 0.23 \mathrm{mmol}, 1.0$ equiv) was dissolved in dry DMF (15 mL) and $\mathrm{NaH}(10.0 \mathrm{mg}, 0.25 \mathrm{mmol}, 1.1$ equiv) was added slowly, then the mixture was stirred in an ice bath for $0.5 \mathrm{~h}$. The solution of 4-bromomethylphenylboronic acid pinacol ester (75.0 $\mathrm{mg}, 0.25 \mathrm{mmol}, 1.1$ equive) in dry DMF (3 $\mathrm{mL})$ was added dropwise into the reaction and stirred at room temperature for $8 \mathrm{~h}$. Then, the reaction mixture was poured into ice water $(100 \mathrm{~mL})$. The crude products were acquired after filtration and purified directly through flash column chromatography on silica gel (Petroleum ether/Ethyl acetate $=10: 1, \mathrm{v} / \mathrm{v}$ ) to afford 9a as white solid (120.0 mg, 82\% yield). ${ }^{1} \mathrm{H}$ NMR (600 MHz, DMSO- $\left.d_{6}\right): \delta=$ 
$8.07(\mathrm{~d}, J=9.0 \mathrm{~Hz}, 1 \mathrm{H}), 7.69$ (d, $J=8.4 \mathrm{~Hz}, 2 \mathrm{H}), 7.58(\mathrm{dd}, J=8.4,3.0 \mathrm{~Hz}, 1 \mathrm{H}), 7.48$ $(\mathrm{d}, J=8.4 \mathrm{~Hz}, 2 \mathrm{H}), 7.41(\mathrm{td}, J=8.4,3.0 \mathrm{~Hz}, 1 \mathrm{H}), 7.29(\mathrm{~d}, J=2.4 \mathrm{~Hz}, 1 \mathrm{H}), 7.26(\mathrm{dd}, J$ = 8.4, $4.2 \mathrm{~Hz}, 1 \mathrm{H}), 7.09(\mathrm{dd}, J=9.0,2.4 \mathrm{~Hz}, 1 \mathrm{H}), 6.16(\mathrm{~s}, 1 \mathrm{H}), 5.20(\mathrm{~s}, 2 \mathrm{H}), 4.68-$ $4.59(\mathrm{~m}, 1 \mathrm{H}), 3.13(\mathrm{td}, J=12.6,3.6 \mathrm{~Hz}, 1 \mathrm{H}), 3.02-2.93(\mathrm{~m}, 1 \mathrm{H}), 2.71(\mathrm{ddd}, J=15.6$, 5.4, 3.6 Hz, 1H), $2.34(\mathrm{~s}, 3 \mathrm{H}), 1.44(\mathrm{~s}, 9 \mathrm{H}), 1.28(\mathrm{~s}, 12 \mathrm{H}) .{ }^{13} \mathrm{C} \mathrm{NMR}(150 \mathrm{MHz}$, DMSO- $\left.d_{6}\right) \delta=162.81,157.91\left(\mathrm{~d}, J_{c-f}=237.75 \mathrm{~Hz}\right), 155.24,149.38,147.17,141.10$, 135.03, 131.57, 128.64, 128.35, 127.26, $123.76\left(\mathrm{~d}, J_{c-f}=7.05 \mathrm{~Hz}\right), 123.49\left(\mathrm{~d}, J_{c-f}=\right.$ $7.2 \mathrm{~Hz}), 120.91\left(\mathrm{~d}, J_{c-f}=23.4 \mathrm{~Hz}\right), 116.44,115.45,113.99\left(\mathrm{~d}, J_{c-f}=23.1 \mathrm{~Hz}\right), 103.73$, $84.50,84.13,69.94,68.48,40.55,38.44,35.68,27.84,25.14,20.55$. The preparation of compound $9 \mathrm{~b}$ was similar to this procedure.

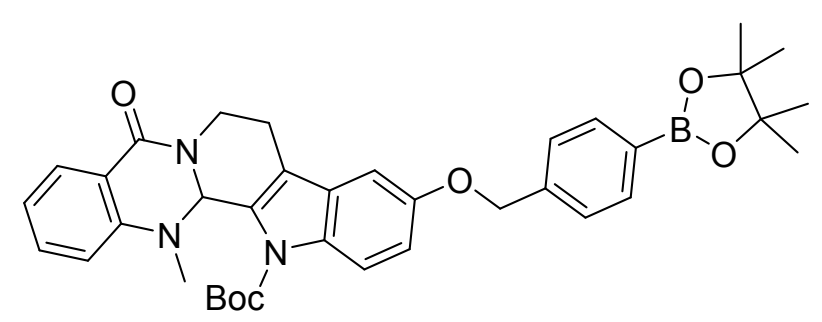

tert-Butyl 14-methyl-5-oxo-10-((4-(4,4,5,5-tetramethyl-1,3,2-dioxaborolan-2-yl)be nzyl)oxy)-7,8,13b,14-tetrahydroindolo $\left[2^{\prime}, 33^{\prime}: 3,4\right]$ pyrido[2,1-b]quinazoline-13(5H)carboxylate (9b). Pale yellow solid, yield 40\%. ${ }^{1} \mathrm{H}$ NMR (600 MHz, DMSO- $\left.d_{6}\right) \delta=$ $8.08(\mathrm{~d}, J=9.0 \mathrm{~Hz}, 1 \mathrm{H}), 7.89(\mathrm{dd}, J=7.8,1.2 \mathrm{~Hz}, 1 \mathrm{H}), 7.70(\mathrm{~d}, J=7.8 \mathrm{~Hz}, 2 \mathrm{H}), 7.55$ - $7.50(\mathrm{~m}, 1 \mathrm{H}), 7.50(\mathrm{~d}, J=7.8 \mathrm{~Hz}, 2 \mathrm{H}), 7.31(\mathrm{~d}, J=2.4 \mathrm{~Hz}, 1 \mathrm{H}), 7.16(\mathrm{~d}, J=8.4 \mathrm{~Hz}$, $1 \mathrm{H}), 7.10(\mathrm{dt}, J=9.0,2.4 \mathrm{~Hz}, 2 \mathrm{H}), 6.16(\mathrm{~s}, 1 \mathrm{H}), 5.31-5.11(\mathrm{~m}, 2 \mathrm{H}), 4.62(\mathrm{dd}, J=$ $10.5,4.8 \mathrm{~Hz}, 1 \mathrm{H}), 3.11(\mathrm{td}, J=12.6,3.6 \mathrm{~Hz}, 1 \mathrm{H}), 3.00(\mathrm{~d}, J=14.4 \mathrm{~Hz}, 1 \mathrm{H}), 2.81$ $2.65(\mathrm{~m}, 1 \mathrm{H}), 2.44(\mathrm{~s}, 3 \mathrm{H}), 1.45(\mathrm{~s}, 9 \mathrm{H}), 1.29(\mathrm{~s}, 12 \mathrm{H}),{ }^{13} \mathrm{C} \mathrm{NMR}(150 \mathrm{MHz}$, DMSO- $\left.d_{6}\right) \delta=163.92,155.25,150.46,149.40,141.11,135.04,133.45,131.50$, $128.81,128.45,127.27,122.00,121.87,120.00,116.51,115.44,103.75,84.57,84.14$, 69.94, 68.27, 40.55, 38.39, 35.19, 27.84, 25.15, 20.67. HRMS (ESI) calcd for $\mathrm{C}_{37} \mathrm{H}_{43} \mathrm{BN}_{3} \mathrm{O}_{6}[\mathrm{M}+\mathrm{H}]^{-}=636.3239$, found 636.3253 . 
<smiles>CN1c2ccc(F)cc2C(=O)N2CCc3c([nH]c4ccc(OCc5ccc(B6OC(C)(C)C(C)(C)O6)cc5)cc34)C21</smiles>

3-Fluoro-14-methyl-10-((4-(4,4,5,5-tetramethyl-1,3,2-dioxaborolan-2-yl)benzyl)o xy)-8,13,13b,14-tetrahydroindolo $\left[2^{\prime}, 3^{\prime}: 3,4\right]$ pyrido $[2,1-b] q u i n a z o l i n-5(7 H)$-one

(10a). To a solution of compound 9a (100.0mg, $0.15 \mathrm{mmol}, 1.0$ equiv) in DCM (20 $\mathrm{mL})$, TFA $(5 \mathrm{~mL})$ was added slowly. Then the mixture was stirred at room temperature for $2 \mathrm{~h}$. After reaction, the mixture was purified directly through flash column chromatograph on silica gel (Petroleum ether/Ethyl acetate $=8: 1, \mathrm{v} / \mathrm{v})$ to afford 10a as a pale yellow solid (40.0 mg, yield 48\%). ${ }^{1} \mathrm{H}$ NMR (600 MHz, DMSO- $\left.d_{6}\right): \delta=11.02(\mathrm{~s}, 1 \mathrm{H}), 7.68(\mathrm{~d}, J=7.8 \mathrm{~Hz}, 2 \mathrm{H}), 7.52(\mathrm{dd}, J=9.0,3.0 \mathrm{~Hz}, 1 \mathrm{H})$, $7.46(\mathrm{~d}, J=8.4 \mathrm{~Hz}, 2 \mathrm{H}), 7.37$ (td, $J=8.4,3.0 \mathrm{~Hz}, 1 \mathrm{H}), 7.25$ (d, $J=9.0 \mathrm{~Hz}, 1 \mathrm{H}), 7.17$ $(\mathrm{dd}, J=9.0,4.2 \mathrm{~Hz}, 1 \mathrm{H}), 7.08(\mathrm{~d}, J=2.4 \mathrm{~Hz}, 1 \mathrm{H}), 6.84(\mathrm{dd}, J=8.4,2.4 \mathrm{~Hz}, 1 \mathrm{H}), 6.05$ $(\mathrm{s}, 1 \mathrm{H}), 5.12(\mathrm{~s}, 2 \mathrm{H}), 4.64-4.55(\mathrm{~m}, 1 \mathrm{H}), 3.22-3.14(\mathrm{~m}, 1 \mathrm{H}), 2.87$ - $2.75(\mathrm{~m}, 2 \mathrm{H})$, $2.66(\mathrm{~s}, 3 \mathrm{H}), 1.28(\mathrm{~s}, 12 \mathrm{H}) .{ }^{13} \mathrm{C}$ NMR (150 MHz, DMSO, TMS) $\delta=163.52,157.59$ $\left(\mathrm{d}, J_{c-f}=237.15 \mathrm{~Hz}\right), 152.75,146.48,141.69,134.99,132.38,130.80,127.17,126.58$, $122.50\left(\mathrm{~d}, J_{c-f}=7.05 \mathrm{~Hz}\right), 122.12\left(\mathrm{~d}, J_{c-f}=7.2 \mathrm{~Hz}\right), 121.03\left(\mathrm{~d}, J_{\mathrm{c}-\mathrm{f}}=22.95 \mathrm{~Hz}\right)$, $113.86\left(\mathrm{~d}, J_{c-f}=23.25 \mathrm{~Hz}\right), 113.12,112.83,111.89,102.33,84.11,70.07,69.74$, 40.83, 37.07, 25.15, 20.10. HRMS (ESI) calcd for $\mathrm{C}_{32} \mathrm{H}_{34} \mathrm{BFN}_{3} \mathrm{O}_{4}[\mathrm{M}+\mathrm{H}]^{+}=$ 554.2621, found 554.2606. The preparation of compound 10b was similar to this procedure.

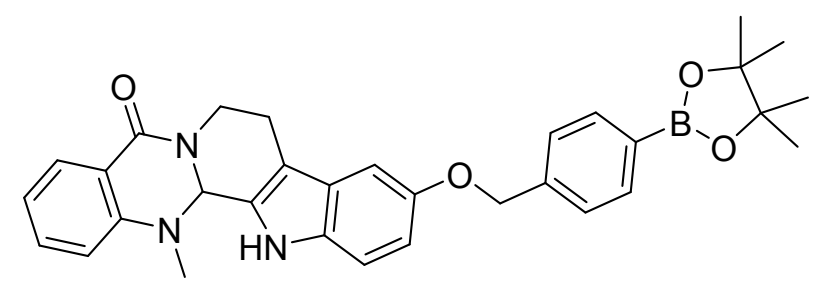

14-Methyl-10-((4-(4,4,5,5-tetramethyl-1,3,2-dioxaborolan-2-yl)benzyl)oxy)-8,13,1 3b,14-tetrahydroindolo $\left[2^{\prime}, 3^{\prime}: 3,4\right]$ pyrido[2,1-b]quinazolin-5(7H)-one (10b). Pale yellow solid, yield 63\%. ${ }^{1} \mathrm{H}$ NMR (600 MHz, DMSO- $\left.d_{6}\right) \delta=10.91(\mathrm{~s}, 1 \mathrm{H}), 7.79$ (dd, 
$J=7.8,1.2 \mathrm{~Hz}, 1 \mathrm{H}), 7.69(\mathrm{~d}, J=7.8 \mathrm{~Hz}, 2 \mathrm{H}), 7.47(\mathrm{~d}, J=7.8 \mathrm{~Hz}, 3 \mathrm{H}), 7.47$ - $7.45(\mathrm{~m}$, 1H), $7.25(\mathrm{~d}, J=9.0 \mathrm{~Hz}, 1 \mathrm{H}), 7.06(\mathrm{~d}, J=2.4 \mathrm{~Hz}, 1 \mathrm{H}), 7.04(\mathrm{~d}, J=7.8 \mathrm{~Hz}, 1 \mathrm{H}), 6.95$ (t, $J=7.2 \mathrm{~Hz}, 1 \mathrm{H}), 6.83(\mathrm{dd}, J=9.0,2.4 \mathrm{~Hz}, 1 \mathrm{H}), 6.09(\mathrm{~s}, 1 \mathrm{H}), 5.13(\mathrm{~s}, 2 \mathrm{H}), 4.62(\mathrm{dd}$, $J=12.6,4.8 \mathrm{~Hz}, 1 \mathrm{H}), 3.18(\mathrm{td}, J=12.0,3.6 \mathrm{~Hz}, 1 \mathrm{H}), 2.91-2.80(\mathrm{~m}, 4 \mathrm{H}), 2.73(\mathrm{dd}, J$ $=15.0,4.2 \mathrm{~Hz}, 1 \mathrm{H}), 1.29(\mathrm{~s}, 12 \mathrm{H}) .{ }^{13} \mathrm{C} \mathrm{NMR}\left(150 \mathrm{MHz}, \mathrm{DMSO}-d_{6}\right) \delta=164.67$, $152.74,149.21,141.68,134.97,133.90,132.21,131.86,128.45,127.17,126.74$, 120.67, 119.66, 117.82, 112.97, 112.81, 111.76, 102.26, 84.10, 70.26, 70.08, 41.36, 36.87, 31.62, 30.30, 25.14, 20.02. HRMS (ESI) calcd for $\mathrm{C}_{32} \mathrm{H}_{35} \mathrm{BN}_{3} \mathrm{O}_{4}[\mathrm{M}+\mathrm{H}]^{-}=$ 536.2715, found 536.2734.<smiles>CC1(C)OB(c2ccc(COC(=O)Oc3ccc([N+](=O)[O-])cc3)cc2)OC1(C)C</smiles>

4-Nitrophenyl (4-(4,4,5,5-tetramethyl-1,3,2-dioxaborolan-2-yl)benzyl) carbonate (12). Compound 11 (585.0 mg, $5.01 \mathrm{mmol}, 1.0$ equiv) and 4-nitrophenyl chloroformate (560.0 mg, $5.53 \mathrm{mmol}, 1.1$ equiv) were dissolved in dry THF (10 mL), followed by the addition of triethylamine (TEA) $(0.7 \mathrm{~mL}, 10.02 \mathrm{mmol}, 2$ equiv) with dropwise. The mixture was stirred at room temperature for $6 \mathrm{~h}$ and then purified through flash column chromatograph on silica gel (Petroleum ether/Ethyl acetate $=10$ : 1, v/v) to afford 12 as white solid (490.0 mg, yield 58\%). ${ }^{1} \mathrm{H}$ NMR (600 MHz, $\left.\mathrm{CDCl}_{3}\right): \delta=8.27-8.23(\mathrm{~m}, 2 \mathrm{H}), 7.84(\mathrm{~d}, J=7.8 \mathrm{~Hz}, 2 \mathrm{H}), 7.43(\mathrm{~d}, J=7.8 \mathrm{~Hz}, 2 \mathrm{H})$, $7.38-7.34(\mathrm{~m}, 2 \mathrm{H}), 5.30(\mathrm{~s}, 2 \mathrm{H}), 1.34(\mathrm{~s}, 12 \mathrm{H})$.<smiles>CN1c2ccc(F)cc2C(=O)N2CCc3c([nH]c4ccc(OC(=O)OCc5ccc(B6OC(C)(C)C(C)(C)O6)cc5)cc34)C21</smiles>

3-Fluoro-14-methyl-5-oxo-5,7,8,13,13b,14-hexahydroindolo[2',3' $: 3,4]$ pyrido $[2,1-b$ lquinazolin-10-yl (4-(4,4,5,5-tetramethyl-1,3,2-dioxaborolan-2-yl)benzyl) 
carbonate (13a). To a stirred solution of compound 1a (310.0 mg, $9.23 \mathrm{mmol}, 1.2$ equiv) and compound 12 (300.0 mg, $7.69 \mathrm{mmol}, 1.0$ equiv) in THF (15 mL), $\mathrm{K}_{2} \mathrm{CO}_{3}$ (290.0 mg, $18.50 \mathrm{mmol}, 2.4$ equiv) was added. The mixture was refluxed at $70{ }^{\circ} \mathrm{C}$ for $10 \mathrm{~h}$. Then, the solvent was evaporated and the residue was purified directly through flash column chromatograph on silica gel (Petroleum ether/Ethyl acetate $=8: 1-4: 1$, $\mathrm{v} / \mathrm{v}$ ) to give 13a as a white solid (280.0 mg, yield 57\%). ${ }^{1} \mathrm{H}$ NMR (600 MHz, DMSO- $\left.d_{6}\right): \delta=11.34(\mathrm{~s}, 1 \mathrm{H}), 7.71(\mathrm{~d}, J=7.8 \mathrm{~Hz}, 2 \mathrm{H}), 7.53(\mathrm{dd}, J=9.0,3.0 \mathrm{~Hz}, 1 \mathrm{H})$, $7.45(\mathrm{~d}, J=8.4 \mathrm{~Hz}, 2 \mathrm{H}), 7.40-7.35(\mathrm{~m}, 2 \mathrm{H}), 7.35$ (d, $J=1.8 \mathrm{~Hz}, 1 \mathrm{H}), 7.19$ (dd, $J=$ 9.0, 4.8 Hz, 1H), $6.97(\mathrm{dd}, J=9.0,2.4 \mathrm{~Hz}, 1 \mathrm{H}), 6.10$ (s, 1H), 5.27 (s, 2H), $4.68-4.53$ $(\mathrm{m}, 1 \mathrm{H}), 3.27-3.13(\mathrm{~m}, 1 \mathrm{H}), 2.86-2.80(\mathrm{~m}, 2 \mathrm{H}), 2.67(\mathrm{~s}, 3 \mathrm{H}), 1.29(\mathrm{~s}, 12 \mathrm{H}) .{ }^{13} \mathrm{C}$ NMR (150 MHz, DMSO- $\left.d_{6}\right): \delta=163.47,157.66\left(\mathrm{~d}, J_{c-f}=237.3 \mathrm{~Hz}\right), 154.30,146.45$, 144.67, 139.01, 135.11, 134.99, 131.92, 127.82, 126.26, $122.57\left(\mathrm{~d}, J_{c-f}=7.2 \mathrm{~Hz}\right)$, $122.27\left(\mathrm{~d}, J_{c-f}=7.5 \mathrm{~Hz}\right), 121.06\left(\mathrm{~d}, J_{c-f}=22.95 \mathrm{~Hz}\right), 116.21,113.87\left(\mathrm{~d}, J_{c-f}=23.4\right.$ Hz), 112.57, 112.48, 110.73, 84.22, 69.75, 69.64, 40.75, 37.19, 25.14, 19.96. HRMS (ESI) calcd for $\mathrm{C}_{33} \mathrm{H}_{34} \mathrm{BFN}_{3} \mathrm{O}_{6}[\mathrm{M}+\mathrm{H}]^{-}=598.2519$, found 598.2546. The preparation of compound $\mathbf{1 3 b}$ was similar to this procedure.

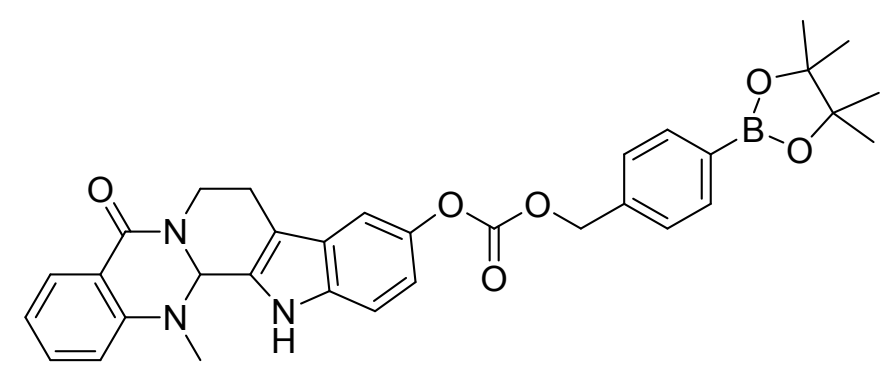

14-Methyl-5-oxo-5,7,8,13,13b,14-hexahydroindolo[2',3' :3,4]pyrido[2,1-b]quinazo lin-10-yl (4-(4,4,5,5-tetramethyl-1,3,2-dioxaborolan-2-yl)benzyl) carbonate (13b). White solid, yield 83\%. ${ }^{1} \mathrm{H}$ NMR (600 MHz, DMSO- $\left.d_{6}\right): \delta=11.22(\mathrm{~s}, 1 \mathrm{H}), 7.79$ (d, $J$ $=7.2 \mathrm{~Hz}, 1 \mathrm{H}), 7.72(\mathrm{~d}, J=8.4 \mathrm{~Hz}, 2 \mathrm{H}), 7.48(\mathrm{~d}, J=7.2 \mathrm{~Hz}, 1 \mathrm{H}), 7.46(\mathrm{~d}, J=7.8 \mathrm{~Hz}$, 2H), $7.36(\mathrm{~d}, J=9.0 \mathrm{~Hz}, 1 \mathrm{H}), 7.32(\mathrm{~d}, J=1.8 \mathrm{~Hz}, 1 \mathrm{H}), 7.05(\mathrm{~d}, J=8.4 \mathrm{~Hz}, 1 \mathrm{H}), 6.947$ - 6.978(m, 2H), $6.14(\mathrm{~s}, 1 \mathrm{H}), 5.28(\mathrm{~s}, 2 \mathrm{H}), 4.62(\mathrm{dd}, J=12.6,5.4 \mathrm{~Hz}, 1 \mathrm{H}), 3.20(\mathrm{td}, J$ $=12.6,4.8 \mathrm{~Hz}, 1 \mathrm{H}), 2.92-2.84(\mathrm{~m}, 4 \mathrm{H}), 2.76(\mathrm{dd}, J=15.0,4.2 \mathrm{~Hz}, 1 \mathrm{H}), 1.30(\mathrm{~s}$, $12 \mathrm{H}) .{ }^{13} \mathrm{C}$ NMR (150 MHz, DMSO- $\left.d_{6}\right): \delta=166.02,155.65,150.55,146.03,140.39$, 
$136.48,136.17,135.32,134.35,129.84,129.19,127.79,122.19,121.08,119.35$, $117.46,113.94,113.72,111.98,85.60,71.53,71.10,42.66,41.93,38.39,26.52$, 21.25. HRMS (ESI) calcd for $\mathrm{C}_{33} \mathrm{H}_{35} \mathrm{BN}_{3} \mathrm{O}_{6}[\mathrm{M}+\mathrm{H}]^{+}=580.2613$, found 580.2635.<smiles>CN1c2ccccc2C(=O)N2CCc3c([nH]c4ccc(OC(=O)OCc5ccc(Br)cc5)cc34)C21</smiles>

\section{3-Fluoro-14-methyl-5-oxo-5,7,8,13,13b,14-hexahydroindolo $\left[2^{\prime}, 3\right.$ ':3,4]pyrido}

[2,1-b]quinazolin-10-yl (4-(trifluoro- $\lambda^{4}$-boranyl)benzyl) carbonate, potassium salt (14a). Aqueous $\mathrm{KHF}_{2}(210 \mu \mathrm{L}, 4.5 \mathrm{M}, 0.95 \mathrm{mmol}, 5.7$ equiv) was added to a suspension of compound 13a (100.0 mg, $0.17 \mathrm{mmol}, 1.0$ equiv) in methanol (2 mL). The resulting mixture was stirred at room temperature for $0.5 \mathrm{~h}$, then solvent was removed under vacuum, acetone $(10 \mathrm{~mL})$ was added and heated to $57^{\circ} \mathrm{C}$ for $0.5 \mathrm{~h}$. The hot suspension was filtered immediately, the filtrate was concentrated under vacuum. Compound 14a was obtained through recrystallization from DCM $(10 \mathrm{~mL})$ as a yellow solid (140.0 mg, yield 74\%). ${ }^{1} \mathrm{H}$ NMR (600 MHz, Acetone- $\left.d_{6}\right): \delta=10.49$ (s, 1H), 7.63 (dd, $J=9.0,3.0 \mathrm{~Hz}, 1 \mathrm{H}), 7.55$ (d, $J=7.8 \mathrm{~Hz}, 2 \mathrm{H}), 7.45$ (d, $J=8.4 \mathrm{~Hz}$, 1H), $7.38(\mathrm{~d}, J=2.4 \mathrm{~Hz}, 1 \mathrm{H}), 7.30(\mathrm{td}, J=8.6,3.1 \mathrm{~Hz}, 1 \mathrm{H}), 7.25-7.21(\mathrm{~m}, 3 \mathrm{H}), 7.01$ (dd, $J=8.4,2.4 \mathrm{~Hz}, 2 \mathrm{H}), 6.06(\mathrm{~s}, 1 \mathrm{H}), 5.21(\mathrm{~s}, 2 \mathrm{H}), 4.77(\mathrm{dt}, J=7.2,4.2 \mathrm{~Hz}, 1 \mathrm{H})$, $3.26(\mathrm{dt}, J=12.6,7.8 \mathrm{~Hz}, 1 \mathrm{H}), 2.96-2.91(\mathrm{~m}, 2 \mathrm{H}), 2.65(\mathrm{~s}, 3 \mathrm{H})$. The preparation of compound $14 \mathrm{~b}$ was similar to this procedure.

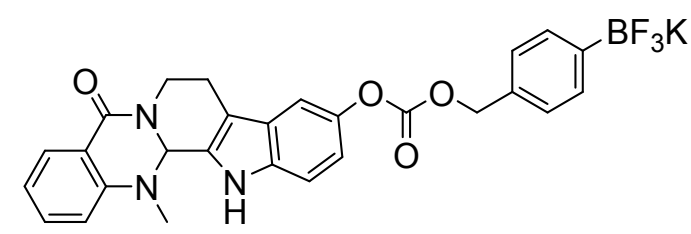

14-Methyl-5-oxo-5,7,8,13,13b,14-hexahydroindolo[2',3' :3,4]pyrido[2,1-b]quinazol in-10-yl (4-(trifluoro- $\lambda^{4}$-boranyl)benzyl) carbonate, potassium salt (14b). Yellow solid, yield 83\%. ${ }^{1} \mathrm{H}$ NMR (600 MHz, Acetone- $\left.d_{6}\right): \delta=10.48(\mathrm{~s}, 1 \mathrm{H}), 7.95(\mathrm{dd}, J=$ 7.8, $1.8 \mathrm{~Hz}, 1 \mathrm{H}), 7.56(\mathrm{~d}, J=7.8 \mathrm{~Hz}, 2 \mathrm{H}), 7.51-7.47(\mathrm{~m}, 1 \mathrm{H}), 7.43(\mathrm{~d}, J=8.4 \mathrm{~Hz}$, 
1H), $7.37(\mathrm{~d}, J=1.8 \mathrm{~Hz}, 1 \mathrm{H}), 7.24(\mathrm{~d}, J=7.8 \mathrm{~Hz}, 2 \mathrm{H}), 7.10(\mathrm{~d}, J=8.4 \mathrm{~Hz}, 1 \mathrm{H}), 7.07$ $7.03(\mathrm{~m}, 1 \mathrm{H}), 6.99(\mathrm{dd}, J=8.7,2.3 \mathrm{~Hz}, 1 \mathrm{H}), 6.08$ (s, 1H), 5.21 (s, 2H), 4.79 (ddd, $J=$ 12.6, 5.4, 1.2 Hz, 1H), 3.25 (ddd, $J=12.6,10.2,4.2 \mathrm{~Hz}, 1 \mathrm{H}), 3.01$ - 2.98 (m, 1H), $2.89(\mathrm{dd}, J=15.6,4.2 \mathrm{~Hz}, 1 \mathrm{H}), 2.84(\mathrm{~s}, 3 \mathrm{H})$.<smiles>CN1c2ccc(F)cc2C(=O)N2CCc3c([nH]c4ccc(OC(=O)OCc5ccc(B(O)O)cc5)cc34)C21</smiles>

(4-(((((3-Fluoro-14-methyl-5-oxo-4a,5,7,8,13,13b,14,14a-octahydroindolo[2',3' :3,4 Ipyrido[2,1-b]quinazolin-10yl)oxy)carbonyl)oxy)methyl)phenyl)boronic acid (15a). TMS-Cl (60 $\mu \mathrm{L}, 0.44 \mathrm{mmol}, 3.1$ equiv) was slowly added to a suspension of compound 14 (118.0 mg, $0.28 \mathrm{mmol} 1.0$ equiv) in the mixture solvent of water (15 $\mu \mathrm{L}$, $0.83 \mathrm{mmol}, 3.1$ equiv) and acetonitrile $(3 \mathrm{~mL})$. Then, the resulting mixture was stirred at room temperature for $1 \mathrm{~h}$. Then it was quenched with saturated sodium bicarbonate solution $(0.3 \mathrm{~mL})$ and dried over with sodium sulfate. After filtration, the filtrate was concentrated under vacuum and the residue was recrystallized from DCM (10 mL) to afford the compound 15a as a white solid (76.0 mg, yield 63\%). ${ }^{1} \mathrm{H}$ NMR (600 MHz, DMSO- $\left.d_{6}\right): \delta=11.31(\mathrm{~s}, 1 \mathrm{H}), 8.05(\mathrm{~s}, 2 \mathrm{H}), 7.80(\mathrm{~d}, J=8.1 \mathrm{~Hz}, 2 \mathrm{H}), 7.51(\mathrm{dd}, J=8.9$, $3.1 \mathrm{~Hz}, 1 \mathrm{H}), 7.38(\mathrm{~d}, J=8.1 \mathrm{~Hz}, 2 \mathrm{H}), 7.35(\mathrm{dd}, J=8.7,3.1 \mathrm{~Hz}, 2 \mathrm{H}), 7.33(\mathrm{~d}, J=2.3$ $\mathrm{Hz}, 1 \mathrm{H}), 7.17$ (dd, $J=8.9,4.5 \mathrm{~Hz}, 1 \mathrm{H}), 6.95$ (dd, $J=8.7,2.4 \mathrm{~Hz}, 1 \mathrm{H}), 6.08$ (s, 1H), $5.24(\mathrm{~s}, 2 \mathrm{H}), 4.65-4.54(\mathrm{~m}, 1 \mathrm{H}), 3.22-3.14(\mathrm{~m}, 2 \mathrm{H}), 2.88-2.76(\mathrm{~m}, 1 \mathrm{H}), 2.66(\mathrm{~s}$, $3 \mathrm{H}) .{ }^{13} \mathrm{C}$ NMR $\left(150 \mathrm{MHz}, \mathrm{DMSO}-d_{6}\right): \delta=163.49,157.65\left(\mathrm{~d}, J_{c-f}=237.3 \mathrm{~Hz}\right)$, $154.35,146.45,144.68,137.39,134.97,134.77,131.91,127.54,126.27,122.54$ (d, $J$ $\left.c_{c-f}=6.9 \mathrm{~Hz}\right), 122.27\left(\mathrm{~d}, J_{c-f}=7.5 \mathrm{~Hz}\right), 121.07\left(\mathrm{~d}, J_{c-f}=23.25 \mathrm{~Hz}\right), 116.24,113.87(\mathrm{~d}$, $\left.J_{c-f}=23.4 \mathrm{~Hz}\right), 112.57,112.48,110.75,70.00,69.64,40.76,40.54,37.19,19.96$. HRMS (ESI) calcd for $\mathrm{C}_{27} \mathrm{H}_{22} \mathrm{BFN}_{3} \mathrm{O}_{6}[\mathrm{M}-\mathrm{H}]^{-}=514.1591$, found 514.1586. The preparation of compound $\mathbf{1 5 b}$ was similar to this procedure. 
<smiles>CN1c2ccccc2C(=O)N2CCc3c([nH]c4ccc(OC(=O)OCc5ccc(B(O)O)cc5)cc34)C21</smiles>

(4-((((14-Methyl-5-oxo-5,7,8,13,13b,14-hexahydroindolo[2',3' :3,4]pyrido[2,1-b]q uinazolin-10-yl)oxy)carbonyl)oxy)methyl)phenyl)boronic acid (15b). White solid, yield 68\%. ${ }^{1} \mathrm{H}$ NMR $\left(600 \mathrm{MHz}, \mathrm{DMSO}-d_{6}\right): \delta=11.20(\mathrm{~s}, 1 \mathrm{H}), 8.07(\mathrm{~s}, 2 \mathrm{H}), 7.82(\mathrm{~d}, J$ $=7.7 \mathrm{~Hz}, 1 \mathrm{H}), 7.78(\mathrm{~d}, J=7.2 \mathrm{~Hz}, 1 \mathrm{H}), 7.49-7.27(\mathrm{~m}, 6 \mathrm{H}), 7.03(\mathrm{~d}, J=8.0 \mathrm{~Hz}, 1 \mathrm{H})$, $6.94(\mathrm{~d}, J=7.6 \mathrm{~Hz}, 2 \mathrm{H}), 6.11(\mathrm{~s}, 1 \mathrm{H}), 5.24(\mathrm{~s}, 2 \mathrm{H}), 4.61(\mathrm{dd}, J=12.5,5.1 \mathrm{~Hz}, 1 \mathrm{H})$, $3.19(\mathrm{dd}, J=12.0,4.5 \mathrm{~Hz}, 1 \mathrm{H}), 2.86(\mathrm{~s}, 4 \mathrm{H}), 2.74(\mathrm{~d}, J=12.5 \mathrm{~Hz}, 1 \mathrm{H}) .{ }^{13} \mathrm{C}$ NMR $(150$ MHz, DMSO- $\left.d_{6}\right) \delta=164.67,154.34,149.19,144.68,137.40,134.79,134.61,133.94$, $132.97,128.48,127.55,126.43,120.82,119.71,117.98,116.12,112.58,112.36$, 110.62, 70.17, 70.00, 41.30, 37.01, 19.89. HRMS (ESI) calcd for $\mathrm{C}_{27} \mathrm{H}_{25} \mathrm{BN}_{3} \mathrm{O}_{6}[\mathrm{M}+$ $\mathrm{H}^{-}=498.1831$, found 498.1853 .

\section{The synthesis of 4-(chloromethyl)phenyl acetate}<smiles>CC(C)(C)OC(=O)Oc1ccc(CO)cc1</smiles>

${ }^{a}$ Reagent and Conditions: (a) Acetyl chloride, TEA, $0{ }^{\circ} \mathrm{C}, 2 \mathrm{~h}$, yield $70 \%$; (b) Dichlorosulfoxide, DMF, rt, 2 h, yield 43\%.<smiles>CC(=O)Oc1ccc(CO)cc1</smiles>

4-(Hydroxymethyl)phenyl acetate. 4-(Hydroxymethyl)phenol (1.0g, 8.06 mmol 1.0 equiv) and TEA $(0.69 \mathrm{~g}, 8.87 \mathrm{mmol} 1.1$ equiv, $630 \mu \mathrm{L})$ were dissolved in DCM (25 $\mathrm{mL})$. Under ice bath, acetyl chloride $(0.89 \mathrm{~g}, 8.87 \mathrm{mmol}, 1.1$ equiv, $1.2 \mathrm{~mL})$ was slowly added to above resulting mixture. Then, the solvent was evaporated and the residue was purified directly through flash column chromatograph on silica gel (Petroleum ether/Ethyl acetate $=5: 1, \mathrm{v} / \mathrm{v}$ ) to give 4-(hydroxymethyl)phenyl acetate as a white solid (914.0 mg, yield 70\%). ${ }^{1} \mathrm{H}$ NMR (300 MHz, DMSO) $: \delta=7.39-7.33$ 
(m, 2H), $7.11-7.04(\mathrm{~m}, 2 \mathrm{H}), 5.26(\mathrm{t}, J=5.76 \mathrm{~Hz}, 1 \mathrm{H}), 4.52(\mathrm{~d}, J=5.76 \mathrm{~Hz}, 2 \mathrm{H}), 2.26$ $(\mathrm{s}, 3 \mathrm{H})$.<smiles>CC(=O)Oc1ccc(CCl)cc1</smiles>

\section{4-(Chloromethyl)phenyl acetate.}

4-(Hydroxymethyl)phenyl acetate (457.0 mg, $2.75 \mathrm{mmol} 1.0$ equiv) was dissolved in dichlorosulfoxide (5 mL). Subsequently, DMF (20.1 mg, $0.275 \mathrm{mmol}, 0.1$ equiv, 21 $\mu \mathrm{L}$ ) was dropped slowly to the mixture. After stirred for $2 \mathrm{~h}$ at room tempareture, the solvent was evaporated and the residue was purified directly through flash column chromatograph on silica gel (Petroleum ether/Ethyl acetate $=15: 1, \mathrm{v} / \mathrm{v})$ to give 4-(chloromethyl)phenyl acetate as a white solid (220.0 mg, yield 43\%). ${ }^{1} \mathrm{H}$ NMR (600 MHz, DMSO) : $\delta=7.54-7.46(\mathrm{~m}, 2 \mathrm{H}), 7.21-7.14(\mathrm{~m}, 2 \mathrm{H}), 4.79$ (s, 2H), 2.29 (s, 3H). ${ }^{13} \mathrm{C}$ NMR (150 MHz, DMSO) $: \delta=169.60,150.81,135.67,130.54,122.52$, 45.98, 21.28. HRMS (ESI) calcd for $\mathrm{C}_{9} \mathrm{H}_{9} \mathrm{ClNaO}_{2}[\mathrm{M}+\mathrm{Na}]^{+}=207.0183$, found 207.0187 .

\section{In vitro cytotoxicity assay}

Antiproliferative activity of compounds were tested against three cell lines (A549, HCT116 and MCF-7). Cells were cultured with mixed medium, which included DMEM medium (Hyclone) or McCoy's 5A medium (Gibco), fetal calf serum (Gibco) and Penicillin-Streptomycin Solution. HCT116 cells were cultured with McCoy's 5A medium, A549 cells and MCF-7 cells were cultured with DMEM (Hyclone). The cells were cultured at $37{ }^{\circ} \mathrm{C}$ in a humidified incubator with $5 \% \mathrm{CO}_{2}$. The three cell lines were purchased from the Chinese Academy of Sciences cell bank.

The cells in logarithmic phase were seeded in 96-well plates at a density of $7 \times 10^{3}$ cells per well and incubated in a humidified atmosphere with $5 \% \mathrm{CO}_{2}$ at $37{ }^{\circ} \mathrm{C}$ for 24 h. Compounds at different concentrations were prepared through triple dilutions and then were added into triplicate wells with a volume of $100 \mu \mathrm{L}$ per well. After cells were incubated with compounds for $72 \mathrm{~h}, \mathrm{CCK} 8 \mathrm{Kit}$ diluted to 10 times with DMEM 
medium was added to each well at a volume of $100 \mu \mathrm{L}$ per well. Then the plates were incubated for additional $0.5 \mathrm{~h}$. The absorbance (OD) was read on a WellscanMK-2 microplate reader (Labsystems) at $450 \mathrm{~nm}$. The concentration causing 50\% inhibition of cell growth $\left(\mathrm{IC}_{50}\right)$ was calculated by the Logit method using Graphd Prism. All assays were repeated three times.

Table S1 In vitro antitumor activity of 4-(chloromethyl)phenyl acetate and 1a

\begin{tabular}{cccc}
$\left(\mathrm{IC}_{\mathbf{5 0}}, \boldsymbol{\mu M}\right)$ & & \\
\hline Compound & HCT116 & MCF-7 & $\mathbf{A 5 4 9}$ \\
\hline 4-(chloromethyl)phenyl acetate & $>30$ & $>30$ & 18 \\
1a & 0.010 & 0.066 & 0.012 \\
\hline
\end{tabular}

\section{Apoptosis detection and cell-cycle arrest assay}

HCT116 cells $\left(4 \times 10^{5}\right.$ cells/well $)$ were seeded in six-well plates. After $24 \mathrm{~h}$, cells were treated with compounds at different concentrations $(0.4 \mu \mathrm{M}, 0.2 \mu \mathrm{M}, 0.05 \mu \mathrm{M})$ for $48 \mathrm{~h}$. Cells were collected by trypsinization and washed once with cold phosphatic buffer solution (PBS) (1.5 mL). After centrifugation and removal of the supernatants, cells were resuspended in cold PBS $(300 \mu \mathrm{L})$, then Binding Buffer $(30 \mu \mathrm{L})$, AnnexinV-FITC $(2 \mu \mathrm{L})$ and Propidium Iodide $(2 \mu \mathrm{L})$ (Becton, Dickinson and Company, catalog numbers: 556547) were added into each tube and incubated at room temperature for $15 \mathrm{~min}$ in the dark. The stained cells were tested through a flow cytometer (BD Accuri C6). The test results were analyzed by FLOW JO software.

HCT116 cells $\left(4 \times 10^{5}\right.$ cells/well $)$ were seeded in six-well plates. After $24 \mathrm{~h}$, cells were treated with compounds at different concentrations $(0.4 \mu \mathrm{M}, 0.2 \mu \mathrm{M}, 0.05 \mu \mathrm{M})$ for $24 \mathrm{~h}$. Cells were collected by trypsinization, washed with cold PBS once and resuspended in DNA staining solution $(300 \mu \mathrm{L})$ and permeabilization solution $(3 \mu \mathrm{L})$ [MultiSciences (Lianke) Biotech Co. Ltd., catalog numbers: CCS012], then incubated for $15 \mathrm{~min}$ at room temperature in the dark. The stained cells were tested through a flow cytometer (BD Accuri C6). For each sample, about $1 \times 10^{4}$ cells were tested. The test results analyzed by Mod Fid software. 


\section{Top1/ Top2 activity inhibitory activity assay}

Assay buffer ( $2 \mu \mathrm{L}$ per sample), bull serum albumin (BSA) $(2 \mu \mathrm{L}$ per sample) and water (15 $\mu \mathrm{L}$ per sample) were mixed and took out mixture $(19 \mu \mathrm{L})$ into first tube. A calculated amount of Top1 enzyme $(0.025 \mu \mathrm{L}, 20 \mathrm{U} / \mu \mathrm{L}$, per sample) (TaKaRa Biotechnology Co., Ltd., Dalian) was added to the remaining mixture and gently vortexed then the mixture was dispensed into a suitable number of tubes $19 \mu \mathrm{L}$ per tube. The first tube and second tube were added of DMSO $(0.5 \mu \mathrm{L})$, the third tube was added of CPT $(0.5 \mu \mathrm{L})$, the remaining tubes were added of the test compounds $(0.5$ $\mu \mathrm{L})$. After vortex, supercoiled pBR322 $(0.5 \mu \mathrm{L}, 0.5 \mu \mathrm{g} / \mu \mathrm{L})$ were added into each tube. Assay mixtures were incubated for $15 \mathrm{~min}$ at $37^{\circ} \mathrm{C}$ and stopped by addition of $10 \times$ loading buffer $(0.9 \%$ sodium dodecyl sulfate (SDS), $0.05 \%$ bromophenol blue, and $50 \%$ glycerol) $(2.2 \mu \mathrm{L})$. Electrophoresis was carried out in a agarose gel (contain $1 \%$ agarose and $99 \%$ TAE) in TAE buffer (Tris-acetate-EDTA) at $85 \mathrm{~V}$ for $1.5 \mathrm{~h}$. Gels were stained with propidium iodide (YeaRed Nucleic Acid Gel Stain 10,000× in Water) for $1 \mathrm{~h}$ and the DNA band was visualized under UV light and photographed with Gel Doc Ez imager (Bio-Rad Laboratories Ltd.).

Assay buffer ( $3 \mu \mathrm{L}$ per sample), adenosine triphosphate (ATP) $(2 \mu \mathrm{L}$ per sample) water (23.5 $\mu \mathrm{L}$ per sample) and pBR322 DNA $(0.4 \mu \mathrm{L}, 0.5 \mu \mathrm{g} / \mu \mathrm{L}$, per sample) were mixed, the mixture was added to appropriate number of tubes $27.9 \mu \mathrm{L}$ per tube. The first one and second one were added of DMSO $(0.6 \mu \mathrm{L})$, the third tube was added of etoposide $(0.6 \mu \mathrm{L})$, the remaining tubes were added of the test compounds $(0.6 \mu \mathrm{L})$. After vortex, calculated amount of Top2 enzyme $(0.02 \mu \mathrm{L}, 10 \mathrm{U} / \mu \mathrm{L}$, per sample) were added to all tubes except the first one. Assay mixtures were incubated for $30 \mathrm{~min}$ at $37{ }^{\circ} \mathrm{C}$ and stopped by addition of $10 \times$ loading buffer $(0.9 \%$ sodium dodecyl sulfate (SDS), $0.05 \%$ bromophenol blue, and $50 \%$ glycerol) $(3.3 \mu \mathrm{L})$. Electrophoresis was carried out in a agarose gel (contain 1\% agarose and 99\% TAE) in TAE buffer (Tris-acetate-EDTA) at $85 \mathrm{~V}$ for $1.5 \mathrm{~h}$. Gels were stained with propidium iodide (YeaRed Nucleic Acid Gel Stain 10,000× in Water) for $1 \mathrm{~h}$ and the DNA band was visualized under UV light and photographed with Gel Doc Ez imager (Bio-Rad Laboratories Ltd.). 


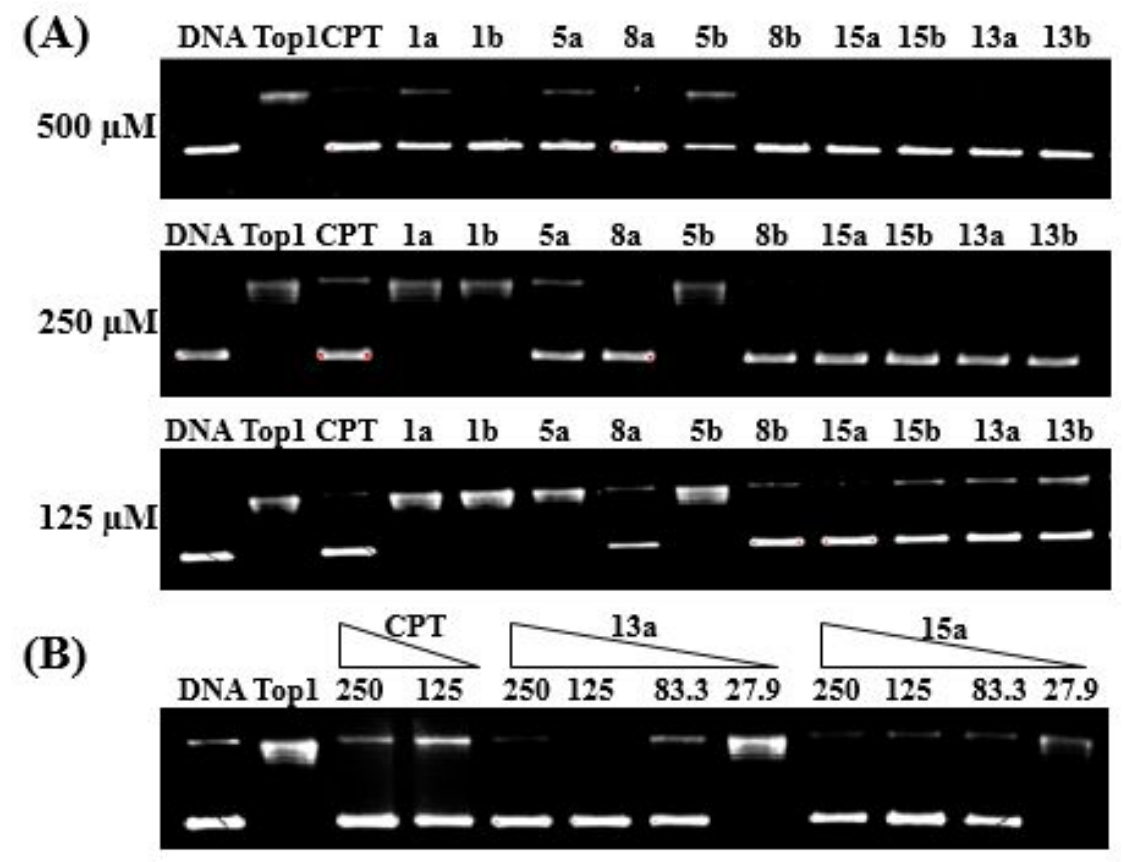

(C) DNA Top2 ETO $1 \mathrm{a}$ la
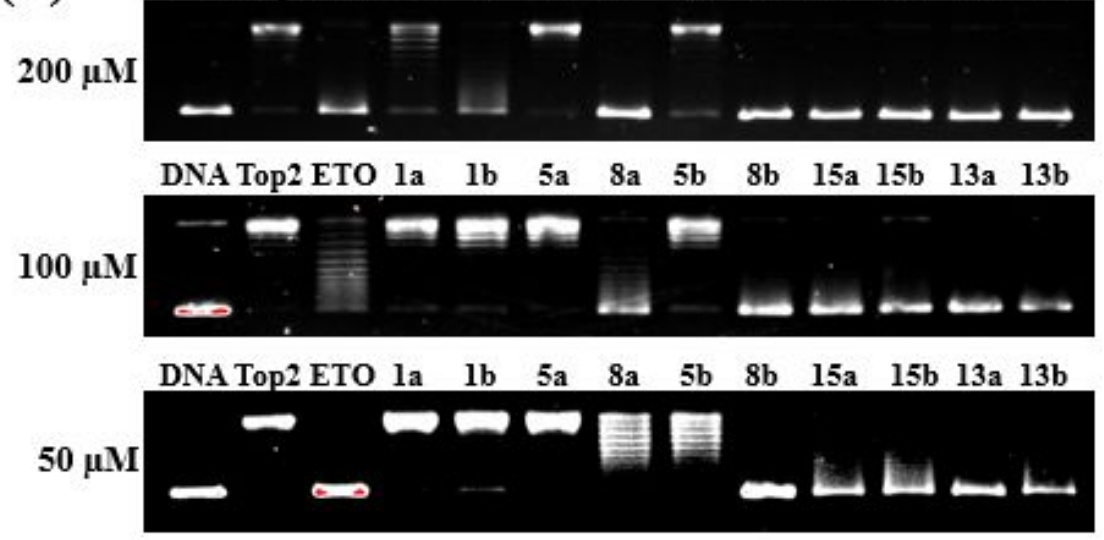

(D)

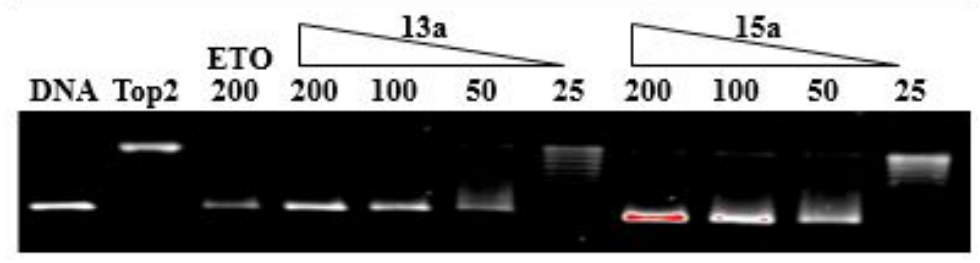

Figure 3. (A) Top1 inhibitory activity assay of evodiamine borate derivatives. Inhibition of Top 1 relaxation activity at $500 \mu \mathrm{M}, 250 \mu \mathrm{M}, 125 \mu \mathrm{M}$ respectively. Lane 1, pBR322 DNA; Lane 2, pBR322 DNA + Top1; Lane 3, pBR322 DNA + Top1 + CPT; Lane 4, pBR322 DNA + Top1 + 1a; Lane 5, pBR322 DNA + Top1 + 1b; Lane6-13, pBR322 DNA + Top1 + derivatives (5a, 8a, 5b, 8b, 15a, 15b, 13a, 13b). (B) Top1 inhibitory activity assay of compounds $13 \mathbf{a}$ and $\mathbf{1 5 a}$ ranging from 27.9 to $250 \mu \mathrm{M}$ : Lane 1, pBR322 DNA; Lane 2, pBR322 DNA + Top1; Lane 3-4, pBR322 DNA + Top 1 + CPT $(250,125 \mu \mathrm{M})$; Lane 5-11, pBR322 DNA + Top1 + 13a (250, 
125, 83.3 and 27.9 $\mu \mathrm{M})$; Lane 12-18, pBR322 DNA + Top1 + 15a $(250,125,83.3$ and $27.9 \mu \mathrm{M})$. (C) Top2 inhibitory activity assay of derivatives: Inhibition of Top2 relaxation activity at $200 \mu \mathrm{M}, 100 \mu \mathrm{M}, 50 \mu \mathrm{M}$ respectively. Lane 1, pBR322 DNA; Lane 2, pBR322 DNA + Top2; Lane 3, pBR322 DNA + Top2 + ETO; Lane 4, pBR322 DNA + Top2 + 1a; Lane 5, pBR322 DNA + Top2 + 1b; Lane 6-13, pBR322 DNA + Top2 + derivatives $(\mathbf{5 a}, \mathbf{8 a}, \mathbf{5 b}, \mathbf{8 b}, \mathbf{1 5 a}, \mathbf{1 5 b}, \mathbf{1 3 a}, \mathbf{1 3 b})$. (D) Top2 inhibitory activity assay of compounds 13a and 15a ranging from 25 to $200 \mu \mathrm{M}$ : Inhibition of Top2 relaxation activity ranging from $25 \mu \mathrm{M}$ to $200 \mu \mathrm{M}$ : Lane 1, pBR322 DNA; Lane 2, pBR322 DNA + Top2; Lane 3, pBR322 DNA + Top2 + ETO; Lane 4-9, pBR322 DNA + Top2 + 13a $(200,100,50$, and $25 \mu \mathrm{M})$; Lane 10-15, pBR322 DNA + Top2 + 15a $(200,100,50$ and $25 \mu \mathrm{M})$.

\section{The binding modes of selected compounds with Top1 and Top2}

Selected compounds were docked into the active site of Top1 (PDB code: 1T8I) and Top2 $\alpha$ (PDB code: $5 \mathrm{GWK}$ ) by a procedure similar to that described previously. Molecular docking was achieved with Maestro 10.2 and the figures were generated using Pymol (http://www.pymol.org/). 

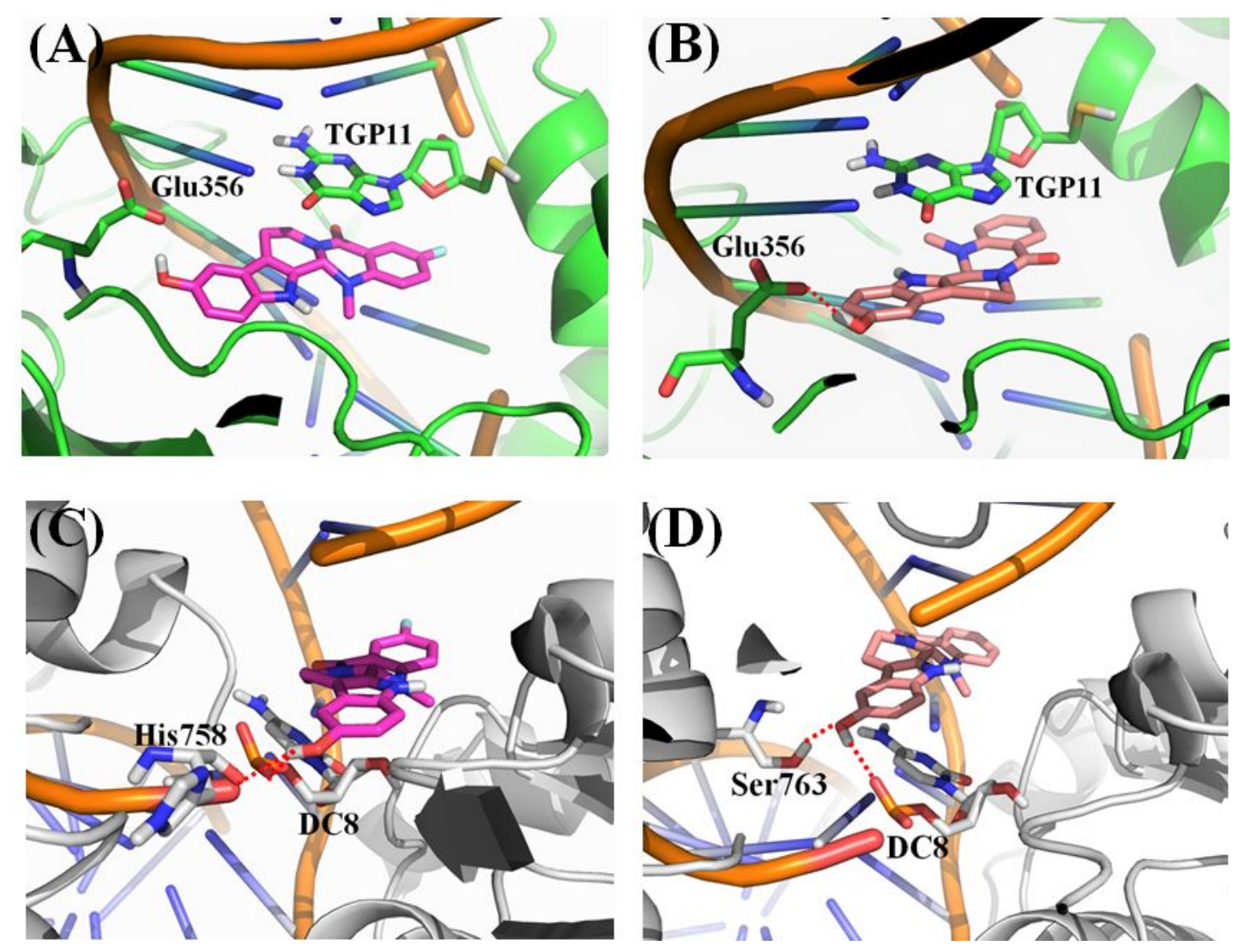

Figure S1. The proposed binding modes for compounds $\mathbf{1 a}(\mathrm{A}, \mathrm{C})$ and $\mathbf{1 b}(\mathrm{B}, \mathrm{D})$ with Top1-DNA complex (PDB code: 1T8I) and ATP-binding domain of Top2 $\alpha$ (PDB code: 5GWK). The figures were generated using Pymol (http://www.pymol.org/).

\section{Determination of in vitro metabolic stability in mice liver microsomes}

The metabolic stability was tested according to the literature. ${ }^{1}$ Liver microsomal incubations were conducted in triplicate. Incubation mixtures $(0.75 \mathrm{mg} / \mathrm{mL}$ microsome protein, $\mathrm{pH} 7.4$ of $100 \mathrm{mM}$ potassium phosphate buffer, $1 \mu \mathrm{M}$ compounds in acetonitrile) were first shaken for pre-incubation at $37{ }^{\circ} \mathrm{C}$. The reaction was initiated by adding NAPDH $(6 \mathrm{mM}, 5 \mathrm{mg} / \mathrm{mL})$ to obtain concentration of $1 \mathrm{mM}$ $\mathrm{NAPDH}$ in the mixture. For metabolic stability studies, aliquots of the incubation sample mixture were collected at $0,5,15,30$ and $45 \mathrm{~min}$. After collection of samples, the reaction was terminated with acetonitrile containing the internal standard (200 $\mathrm{ng} / \mathrm{mL}$ Tolbutamide). The mixture was then centrifuged to remove the protein and the supernatant was subsequently applied to LC-MS/MS analysis. Positive control samples were prepared as described above, except the test compound was replaced with the known substrate ketanserin. 
Table S2 The mice microsomal stability of compounds 13a, 15a and 1a.

\begin{tabular}{ccc}
\hline Compound & $\boldsymbol{t}_{\mathbf{1 / 2}}$ (minute) & $\mathbf{C l}_{\mathbf{i n t}}(\mathbf{m L} / \mathbf{m i n} / \mathbf{k g})$ \\
\hline ketanserin & 23.79 & 229.42 \\
$\mathbf{1 3 a}$ & 8.36 & 653.16 \\
$\mathbf{1 5 a}$ & 0.74 & 7395.17 \\
$\mathbf{1 a}$ & 3.69 & 1479.84 \\
\hline
\end{tabular}

\section{Tubulin polymerization inhibitory activity assay}

The tubulin polymerization assay was performed according to the literature. ${ }^{2} \mathrm{~A}$ purified brain tubulin polymerization kit was purchased from Cytoskeleton (BK006P, Denver, CO). The final assay buffer, which contained 0.1 M MES (pH 6.6), $10 \mathrm{mM}$ $\mathrm{MgCl}_{2}, 1 \mathrm{mM}$ GTP, $1 \mathrm{mM}$ EGTA, and $3.4 \mathrm{M}$ glycerol, was cooled to $0{ }^{\circ} \mathrm{C}$. Compounds was added at different concentrations, and the reaction was initiated by the addition of tubulin to a final concentration of $10 \mathrm{mM}$ with warming to $37^{\circ} \mathrm{C}$. Combretastatin A4 (CA4) was used as a positive control under similar experimental conditions. The optical density at $340 \mathrm{~nm}$ was measured at $1 \mathrm{~min}$ intervals for 15 30 min with a BioTek's Synergy 4 multifunction microplate reader, and the values was used to calculate the $\mathrm{IC}_{50}$ values.

Table S3 $\alpha$-Tubulin inhibitory activity

\begin{tabular}{cc}
\hline Compound & $\boldsymbol{\alpha}$-tubulin $\mathbf{I C}_{\mathbf{5 0}}(\boldsymbol{\mu M})$ \\
\hline $\mathbf{1 3 a}$ & $>100$ \\
$\mathbf{1 3 b}$ & $>100$ \\
$\mathbf{1 5 a}$ & $25.7 \pm 2.2$ \\
$\mathbf{1 5 b}$ & $>100$ \\
$\mathbf{C A 4}$ & $1.0 \pm 0.2$ \\
\hline
\end{tabular}

\section{0. cLogP prediction}

The cLogP of compounds 13, 15 and 1 were predicted by website: http://www.scfbioiitd.res.in/software/drugdesign/lipinski.jsp 
Table S4 The cLogP value of evodiamine analogues

\begin{tabular}{cc}
\hline Compound & cLogP \\
\hline $\mathbf{1 3 a}$ & 5.93 \\
$\mathbf{1 3 b}$ & 5.22 \\
$\mathbf{1 5 a}$ & 2.59 \\
$\mathbf{1 5 b}$ & 0.84 \\
$\mathbf{1 a}$ & 3.16 \\
$\mathbf{1 b}$ & 2.58 \\
\hline
\end{tabular}

\section{Relative drug release by hydrogen peroxide}

Test compounds were prepared in DMSO at concentration of $10 \mathrm{mM}$. Compounds $(10 \mu \mathrm{L}), \mathrm{PBS}$ and hydrogen peroxide $(50 \mathrm{mM}$ or $10 \mathrm{mM})$ were mixed to give a final volume of $100 \mu \mathrm{L}$. The mixture was incubated at $37^{\circ} \mathrm{C}$ for $8 \mathrm{~h}$ and then quenched with equal sodium thiosulfate solution $(50 \mathrm{mM}$ or $10 \mathrm{mM})$. After filtration with 0.22 $\mu \mathrm{m}$ filter membrane, the solution was directly analyzed by HPLC (Eclipse Plus C18, $5 \mu \mathrm{m}, 4.62 .1 \times 250 \mathrm{~mm})$. 


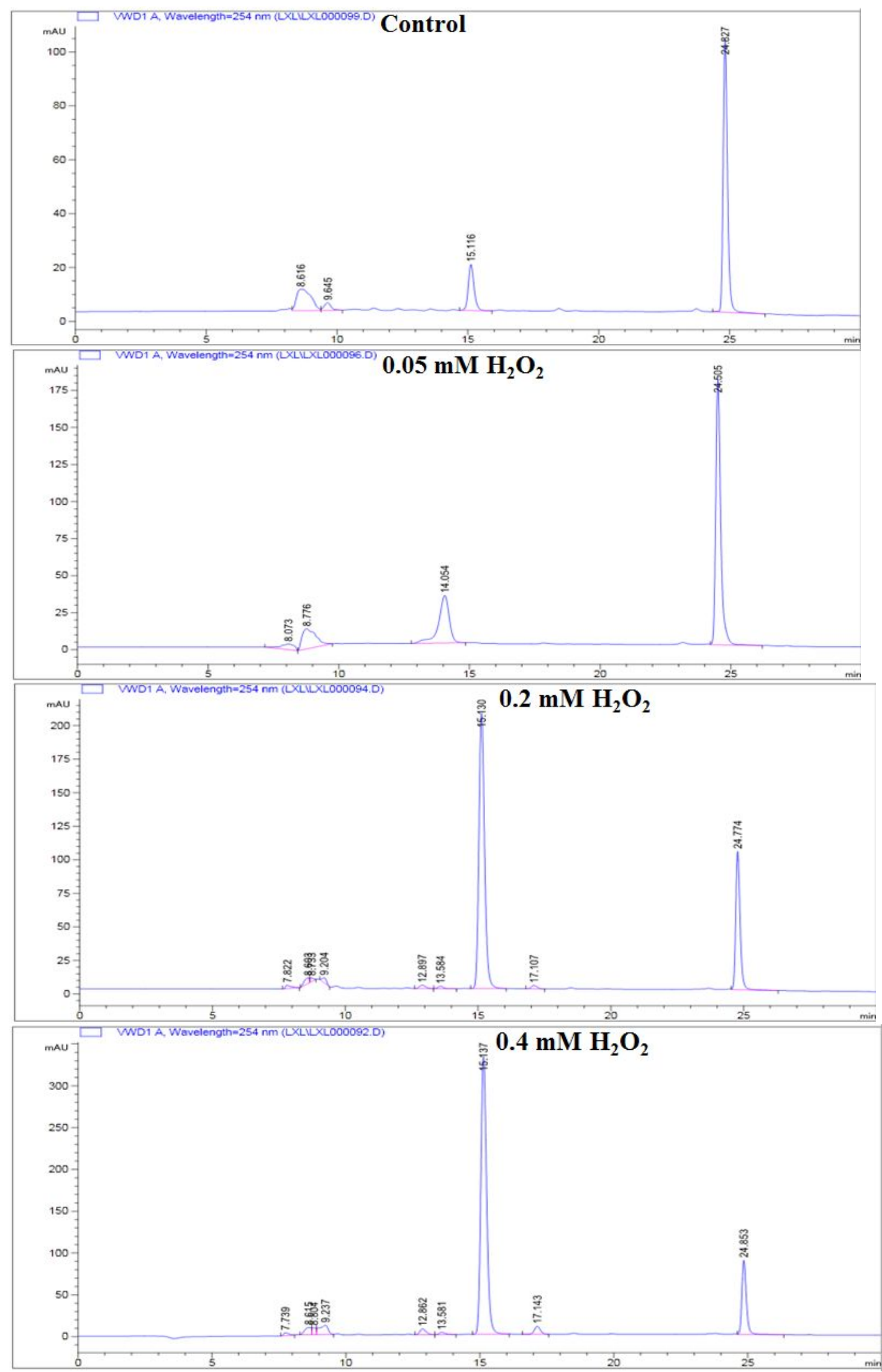

Figure S2. Relative drug release of compound 15a determined by HPLC 

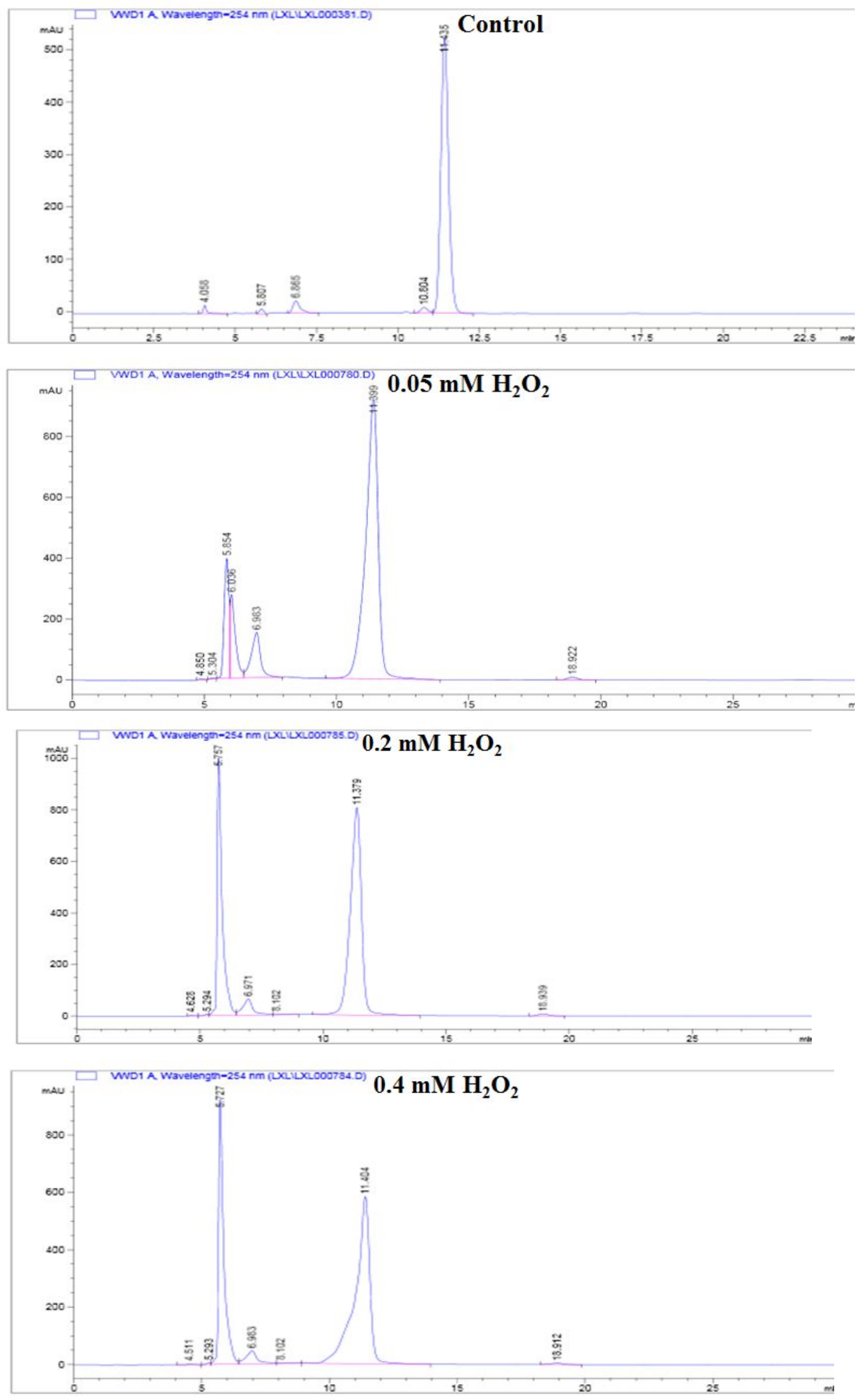

Figure S3. Relative drug release of compound 13a determined by HPLC 
Table S5. Relative drug release rate by $\mathrm{H}_{2} \mathrm{O}_{2}$ and elution conditions

\begin{tabular}{|c|c|c|c|c|}
\hline Compound & $\begin{array}{l}\mathrm{H}_{2} \mathrm{O}_{2}(\%) \\
0.05 \mathrm{mM}\end{array}$ & $\begin{array}{c}\mathrm{H}_{2} \mathrm{O}_{2}(\%) \\
0.2 \mathrm{mM}\end{array}$ & $\begin{array}{c}\mathrm{H}_{2} \mathrm{O}_{2}(\%) \\
0.4 \mathrm{mM}\end{array}$ & Elution conditions \\
\hline $5 \mathbf{a}$ & 10.1 & 19.7 & 25.4 & $\begin{array}{c}\text { methanol } / \text { water }=70: 30 \\
0.25 \mathrm{~mL} / \mathrm{min}\end{array}$ \\
\hline $5 \mathbf{b}$ & 6.3 & 23.7 & 52.1 & $\begin{array}{c}\text { methanol } / \text { water }=70: 30, \\
0.25 \mathrm{~mL} / \mathrm{min}\end{array}$ \\
\hline $13 a$ & 11.6 & 35.6 & 36.4 & $\begin{array}{c}\text { methanol } / \text { water }=90: 10, \\
0.5 \mathrm{~mL} / \mathrm{min}\end{array}$ \\
\hline $15 \mathbf{a}$ & 20.8 & 72.0 & 82.8 & $\begin{array}{c}\text { methanol } / \text { water }=70: 30, \\
0.3 \mathrm{~mL} / \mathrm{min}\end{array}$ \\
\hline $15 b$ & 18.6 & 57.8 & 83.2 & $\begin{array}{c}\text { methanol } / \text { water }=70: 30, \\
0.3 \mathrm{~mL} / \mathrm{min}\end{array}$ \\
\hline
\end{tabular}

\section{Relative drug release by HCT116 cells}

HCT116 cells $\left(1 \times 10^{6}\right.$ cells/well $)$ were seeded in six-well plates. After $24 \mathrm{~h}$, cells were treated with compounds at $0.2 \mathrm{mM}$ for $8 \mathrm{~h}$. Culture medium was collected and extracted with ethyl acetate $(1 \mathrm{~mL})$. After centrifugation, the supernatant (100 $\mu \mathrm{L})$ was diluted with methanol $(100 \mu \mathrm{L})$. The mixture was filtrated with $0.22 \mu \mathrm{m}$ filter membrane, and then directly analyzed on an Agilent UPLC-QTOF/MS system. Chromatographic separations were achieved by using a Waters XBridge ${ }^{\circledR}$ BEH C18 $2.5 \mu \mathrm{m}$ column $(2.1 \times 100 \mathrm{~mm})$. Elution conditions were at flow rate 0.4 $\mathrm{mL} / \mathrm{min}$ with gradient elution (water with $0.1 \%$ formic acid)/(acetonitrile with $0.1 \%$ formic acid) $=95: 5$ for $13 \mathrm{~min}$, (water with $0.1 \%$ formic acid) $/($ acetonitrile with $0.1 \%$ formic acid) $=5: 95$ from $13 \mathrm{~min}$ to $15 \mathrm{~min}$ ).

Total Ion Chromatography (TIC) was measured by chromatography-mass spectrometry to test the total ions of various mass-to-charge ratios and changes over time. Diode array detector (DAD) was used to detect the UV absorption chromatography of compounds under $254 \mathrm{~nm}$. 

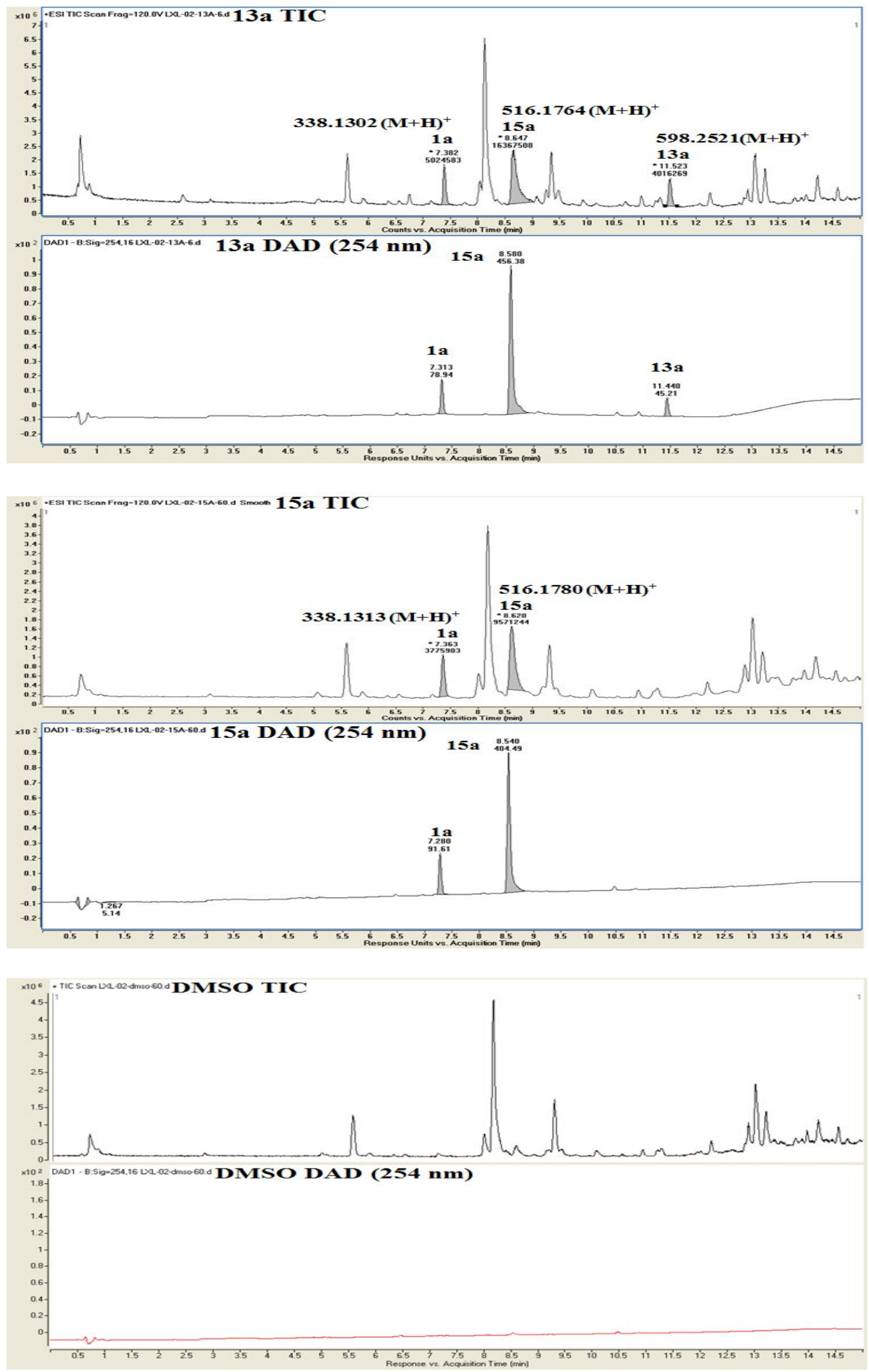

Figure S4. Relative drug release of compound 13a and 15a determined by UPLC- 
QTOF/MS after incubation with HCT116 cells for $8 \mathrm{~h}$.
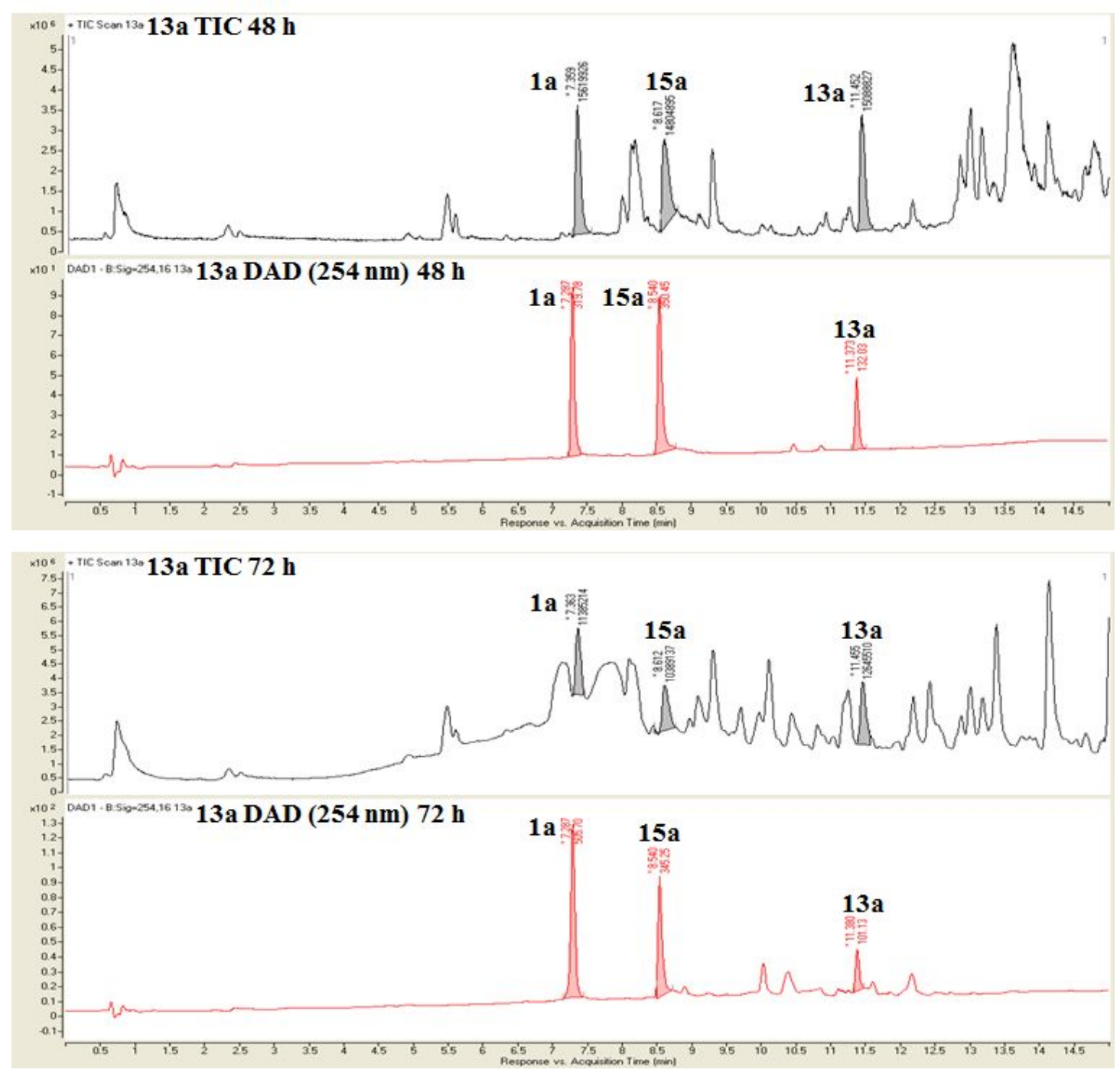

Figure S5. Relative drug time-dependent release of compound 13a determined by UPLC- QTOF/MS after incubation with HCT116 cells for $48 \mathrm{~h}$ and $72 \mathrm{~h}$. 

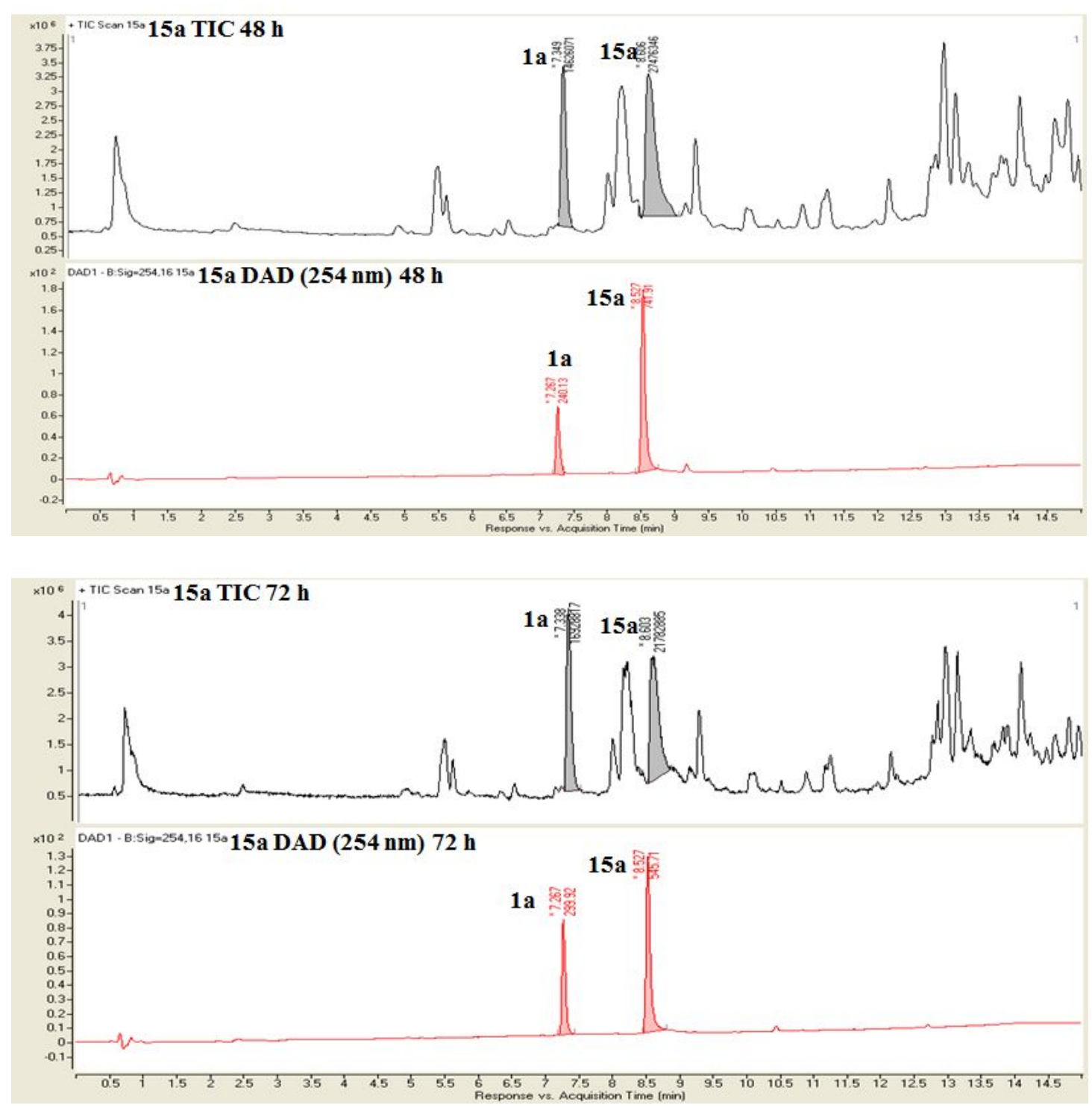

Figure S6. Relative drug time-dependent release of compound 15a determined by UPLC- QTOF/MS after incubation with HCT116 cells for $48 \mathrm{~h}$ and $72 \mathrm{~h}$.

Compound 13a (retention time: $11.4 \mathrm{~min}$ ) was first converted to compound $\mathbf{1 5 a}$ (43.7\%) and then transformed to compound 1a (39.9\%) for $48 \mathrm{~h}$ (Figure S5). Compound 15a (retention time: $8.5 \mathrm{~min}$ ) was directly converted into compound 1a (retention time: $7.3 \mathrm{~min}$ ) with the relative drug release rate of $24.5 \%$ for $48 \mathrm{~h}$ (Figure S6).

Compound 13a (retention time: $11.4 \mathrm{~min}$ ) was first converted to compound $\mathbf{1 5 a}$ (36.3\%) and then transformed to compound 1a (53.1\%) for $72 \mathrm{~h}$ (Figure S5). In contrast, compound 15a (retention time: $8.5 \mathrm{~min}$ ) was directly converted into compound 1a (retention time: $7.3 \mathrm{~min}$ ) with the relative drug release rate of $35.5 \%$ for 


\section{2 h (Figure S6).}

\section{In vivo antitumor activity}

The female nude mice were purchased from Shanghai Jihui Experimental Animal Breeding Co., Ltd. The cultured HCT116 cells were collected, counted and resuspended in cold PBS, then cells were transplanted to the right forelimbs of the female nude mice, $5 \times 10^{6}$ cells/mouse. After 12 days, the solid tumors grown to about $100 \mathrm{~mm}^{3}$, the mice were randomly divided into four groups consisting of 6 mice/group. The mice were injected compounds by intraperitoneal administration once on day or twice on day, mice weight and tumor volume were recorded every two days. Tumor volumes were calculated from formula: TV $=1 / 2 \times a \times b^{2}$, where " $a$ " is the tumor length and " $b$ " is the width and both "a" and " $b$ " were measured by a vernier caliper. Post treatment mice were sacrificed on 22 days, and tumors were removed for further analysis.

The experimental procedures and the animal use and care protocols were approved by the Committee on Ethics of Biomedicine, Second Military Medical University.
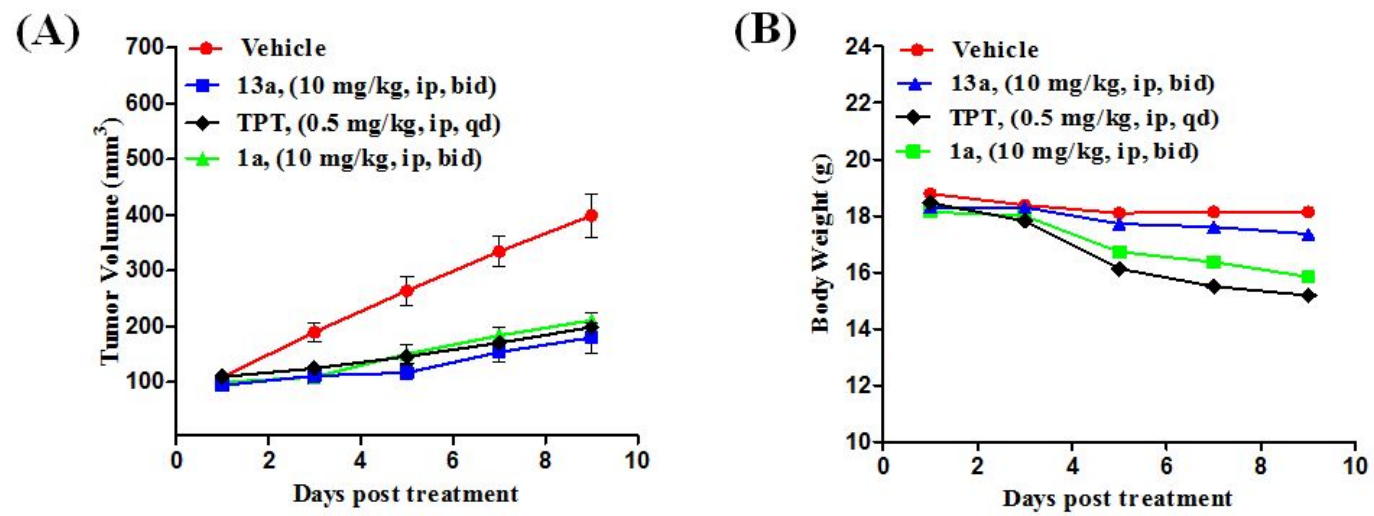

Figure S7. Antitumor efficacy of compounds 1a, 13a and TPT in the xenograft model for 9 days. (A) The efficacy of compounds 1a, 13a in the HCT116 xenograft model. (B) The change of body weight for the nude mice that were treated with compounds 1a, 13a and TPT. 


\section{4. ${ }^{1} \mathrm{H}$ NMR and ${ }^{13} \mathrm{C}$ NMR spectrums}

${ }^{1} \mathrm{H}$ NMR of compound $13 \mathbf{a}$.

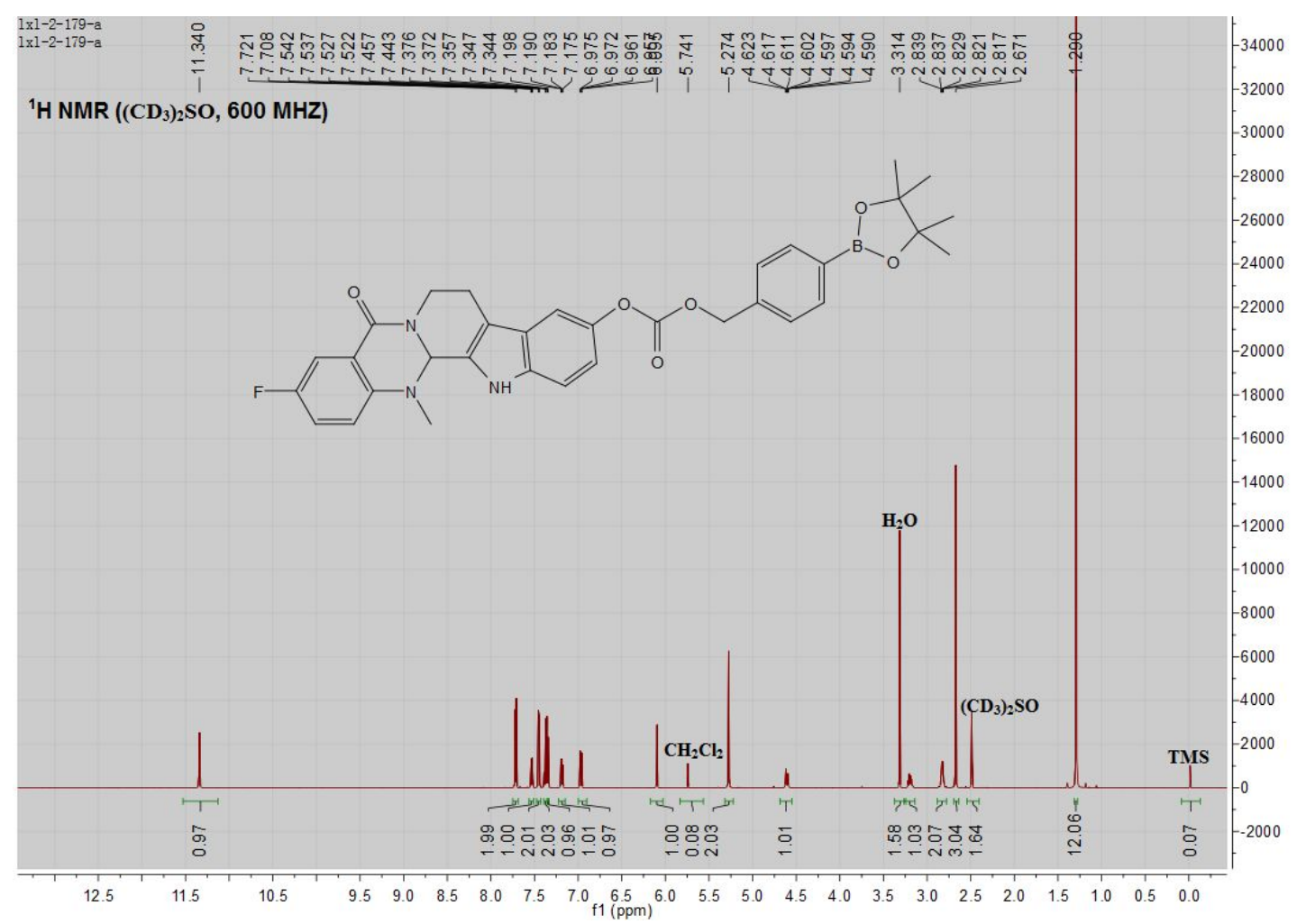

${ }^{13} \mathrm{C}$ NMR of compound 13a.

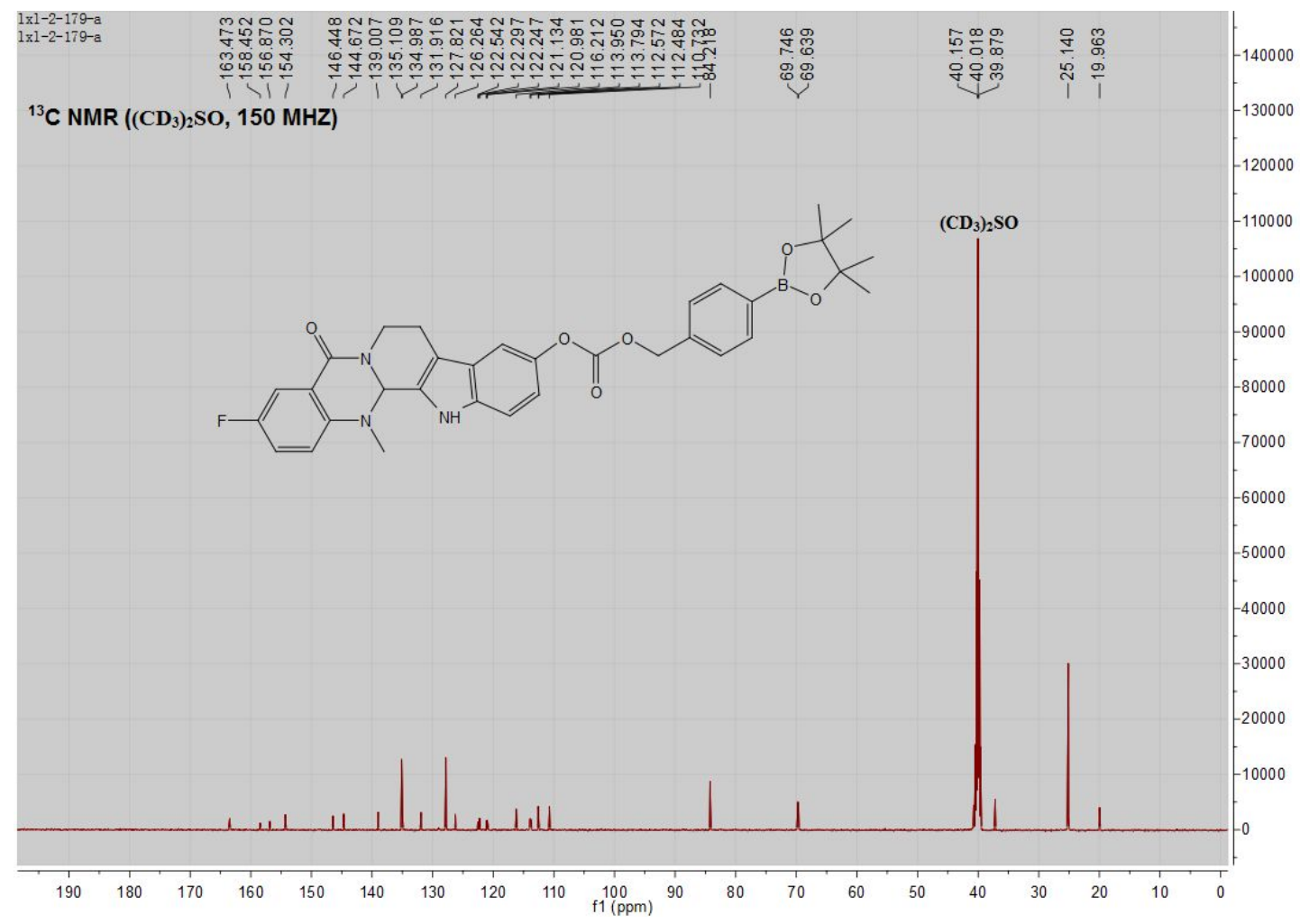


${ }^{1} \mathrm{H}$ NMR of compound 15a.

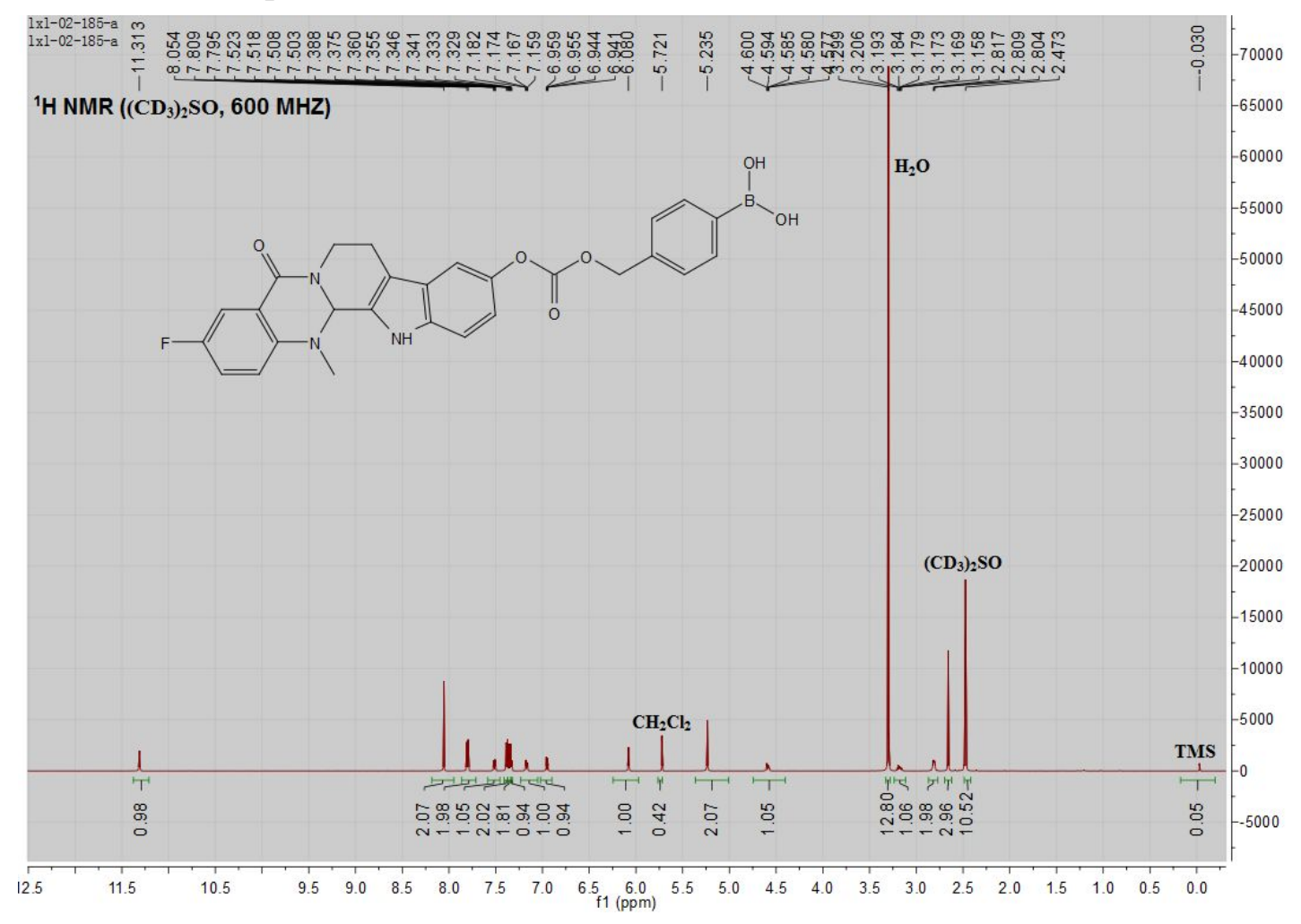

${ }^{13} \mathrm{C}$ NMR of compound 15a.

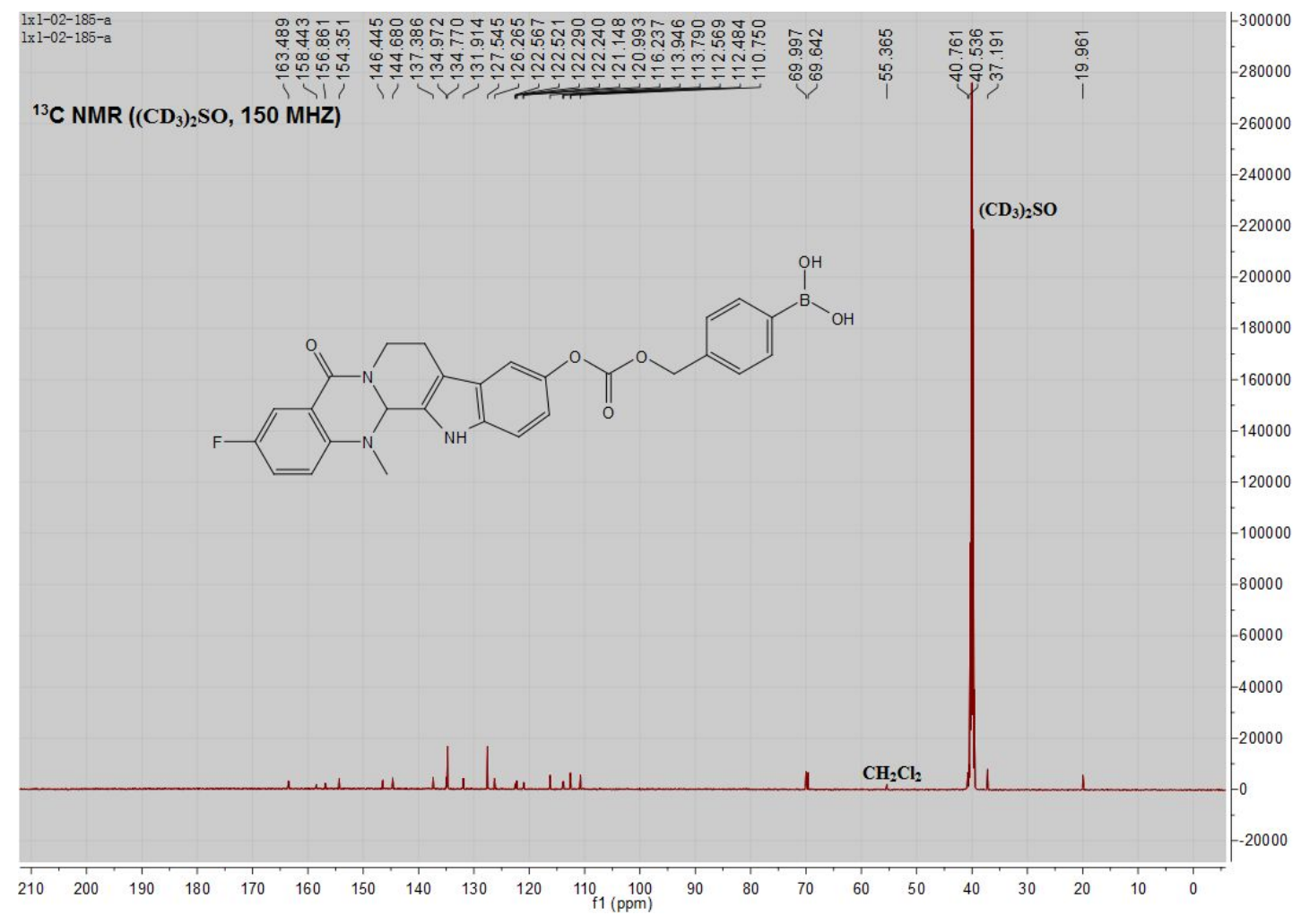




\section{HPLC purity of representative compounds}

\section{HPLC of compound 13a.}

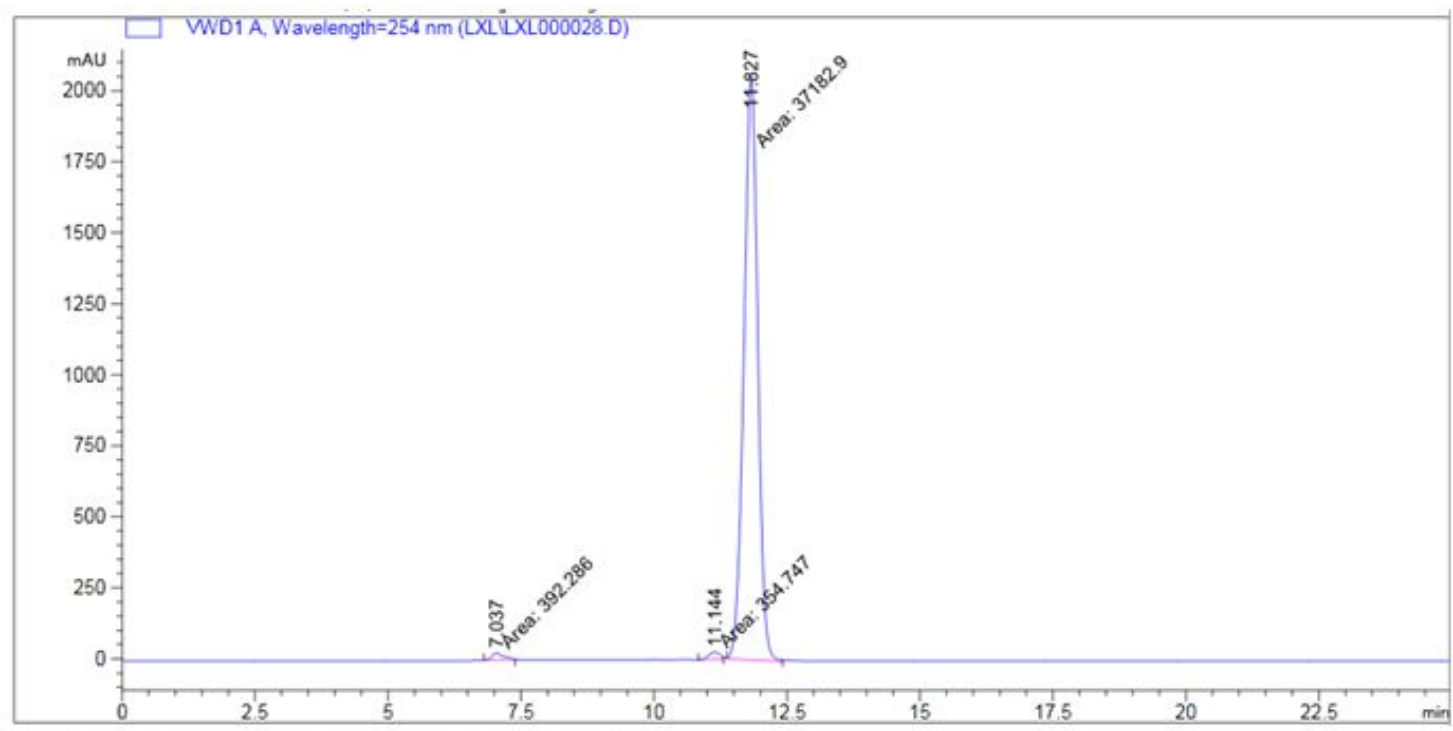

Signal 1: VWD1 A, Wavelength=254 nm

\begin{tabular}{cccccc}
$\begin{array}{c}\text { Peak } \\
\text { \# }\end{array}$ & $\begin{array}{c}\text { RetTime Type } \\
\text { [min] }\end{array}$ & $\begin{array}{c}\text { Width } \\
\text { [min] }\end{array}$ & $\begin{array}{c}\text { Area } \\
\text { [mAU*s] }\end{array}$ & $\begin{array}{c}\text { Height } \\
\text { [mAU] }\end{array}$ & $\begin{array}{c}\text { Area } \\
\text { of }\end{array}$ \\
\hline 1 & $7.037 \mathrm{MM}$ & 0.2598 & 392.28619 & 25.16863 & 1.0342 \\
2 & $11.144 \mathrm{MM}$ & 0.2411 & 354.74719 & 24.52522 & 0.9353 \\
3 & $11.827 \mathrm{MM}$ & 0.3028 & $3.71829 e 4$ & 2046.78564 & 98.0305
\end{tabular}

HPLC of compound 15a.

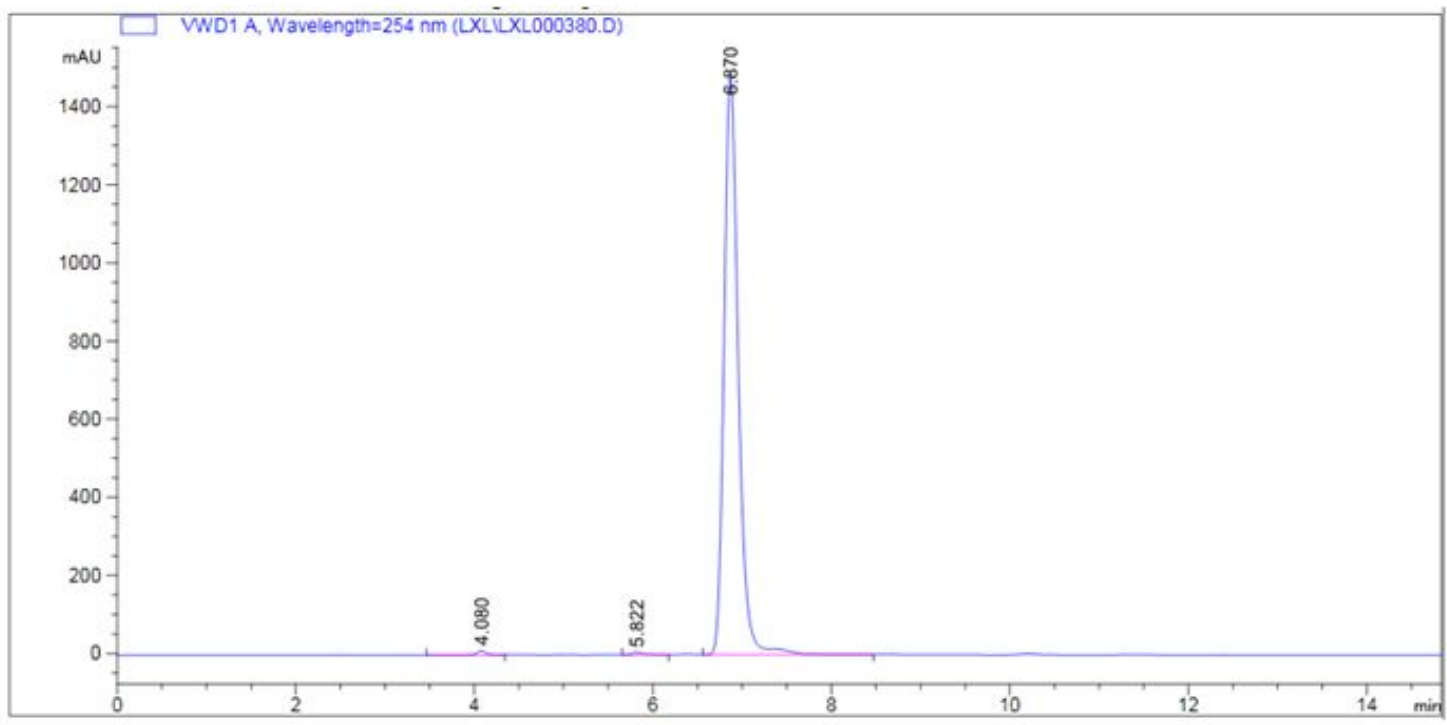

Signal 1: VWD1 A, Wavelength=254 nm

\begin{tabular}{|c|c|c|c|c|c|c|}
\hline $\begin{array}{c}\text { Peak } \\
\#\end{array}$ & $\begin{array}{c}\text { RetTime } \\
\text { [min] }\end{array}$ & Type & $\begin{array}{c}\text { Width } \\
\text { [min] }\end{array}$ & $\begin{array}{c}\text { Area } \\
{\left[\mathrm{mAU}^{\star} \mathrm{s}\right]}\end{array}$ & $\begin{array}{l}\text { Height } \\
{[\mathrm{mAU}]}\end{array}$ & $\begin{array}{c}\text { Area } \\
\&\end{array}$ \\
\hline-- & & & - & ---- & -- & -- \\
\hline 1 & 4.080 & BV & 0.0989 & 76.49403 & 11.36674 & 0.4586 \\
\hline 2 & 5.822 & $\mathrm{VB}$ & 0.1533 & 54.97726 & 5.41901 & 0.3296 \\
\hline 3 & 6.870 & VV & 0.1711 & 1. $65483 e 4$ & 1481.12280 & 99.2118 \\
\hline
\end{tabular}




\section{Certificate of STR analysis}

\section{CBTCCCAS}

\section{Certificate of STR Analysis}

1.Sample
HCT 116
2.2.Methods
The genomic DNA was purified wit
The DNA sample was analysed in
The sample was amplified with
The profiles STR loci and Amelogen
Genetic Analysis Instrument.
3.Results
\[ \begin{array}{ll}\text { D5S818 } & 10,11 \\ \text { D13S317 } & 10,12 \\ \text { D7S820 } & 11,12 \\ \text { D16S539 } & 11,13 \\ \text { vWA } & 17,22 \\ \text { TH01 } & 8,9 \\ \text { Amelogenin } & \text { X,Y } \\ \text { TPOX } & 8,9 \\ \text { CSF1PO } & 7,10\end{array} \]

The above results were consistent with the DNA profiles reported by ATCC, and DSMZ, and indicated no other human cell lines contamination.

Cell Bank,

Type Culture Collection,

Chinese Academy of Sciences

(CBTCCCAS )

$2013 / 7 / 5$

\section{Reference}

1. Huang, Y.; Chen, S.; Wu, S.; Dong, G.; Sheng, C., Evodiamine-inspired dual inhibitors of histone deacetylase 1 (HDAC1) and topoisomerase 2 (TOP2) with potent antitumor activity. Acta Pharm. Sin. B. 2019, https://doi.org/10.1016/j.apsb.2019.11.011. 